\title{
Plutonium Isotopic Composition by Gamma-Ray Spectroscopy: A Review
}

\author{
T. E. Sampson
}

\section{DISCLAIMER}

\begin{abstract}
This report was prepared as an account of work sponsored by an agency of the United States employees. alakes any warranty, express or implied, or assumes any thereof, nor any of their bility for the accuracy, cornpleteness, or usefulness of any inf any legal liability or responsiprocess disclosed, or represents that its use would not infringe privately apparatus, product, $9 r$ manufacturer, or otherwise commercial product, process, or service by owned rights. Refermendation, or farnering does not necessarily constitute or imply trade name, trademark, and opinions of United Statis Governors expressed herein do not necessarily state or thereof. The views United Statas Government or any agency thereof.
necessarily state or reflect those of the
\end{abstract}


I. INTRODUCTION . . . . . . . . . . . . . . . . . . . 1

II. PRELIMINARY CONSIDERATIONS . . . . . . . . . . 2

A. Plutonium Isotope Decay Characteristics . . . 2

B. ${ }^{241}$ Pu Decay . . . . . . . . . . . . . . . 3

C. ${ }^{242} \mathrm{Pu}$. . . . . . . . . . . . . . . 4

D. Spectral Interferences . . . . . . . . . 4

E. Applications . . . . . . . . . . . . 5

IIT. SPECTRAL REGIONS USEFUL FOR ISOTOPIC MEASUREMENTS - 5

A. 40-keV Region . . . . . . . . . . . . . . . 8

B. 100-keV Region ........ . . . . . . . 10

ᄃ. 125-keV Region . . . . . . . . . . . . . 13

D. 148-keV Region . . . . . . . . . . . . . 15

E. 160-keV Region ............... . 17

F. 208-keV Region .. . . . . . . . . . . . 19

G. 332-keV Region . . . . . . . . . . . . . . 21

H. 375-keV Region .. . . . . . . . . . . . 22

I. 640-keV Region . . . . . . . . . . . . 23

IV. MEASUREMENT PRINCIPLES . . . . . . . . . . . . 25

A. Isotopic Ratio/Measurement . . . . . . . 25

B. Absolute Isotopic Mass Measurement . . . . . 31

C. $\quad{ }^{242} \mathrm{Pu}$ Isotopic Correlation . . . . . . . 32

v. DATA ACQUISITION ................ 34

A. Electronics . . . . . . . . . . . . . 34

B. Detectors................. 34

C. Filters................ . 35

D. Sample Considerations . . . . . . . . . 35

E. Counting Time .. . . . . . . . . . . . 37 
VI. DATA ANAlysis . . . . . . . . . . . 37

A. ROI Summation................ 37

B. Peak fitting . . . . . . . . . . . . . 38

c. Response-Function Analysis .......... 41

VII. IMPLEMENTED SYSTEMS . . . . . . . . . . . . . . . 42

A. Rockwell-Hanford . . . . . . . . . . . . . 42

B. Los Alamos . . . . . . . . . . . . . . . 43

C. Mound . . . . . . . . . . . . . . . . . 45

D. Livermore................. 51

E. Precision Summary . . . . . . . . . . . 54

ACKNOWLEDGMENTS . . . . . . . . . . . . . . . . . 55

REFERENCES . . . . . . . . . . . . . . . . . 55 


\section{PLUTONIUM ISOTOPIC COMPOSITION \\ BY GAMMA-RAY SPECTROSCOPY: A REVIEW}

by

T. E. Sampson

\section{ABSTRACT}

This report presents a review of the methods and capabilities of nondestructive measurements of the isotopic composition of plutonium using gamma-ray spectroscopy.

\section{INTRODUCTION}

Accurate and timely accounting for and control of plutonium require that methods be available for measuring plutonium in its various forms. Measurements of the amount of individual isotopes as well as the total amount of plutonium are often required. Gamma-ray spectroscopy techniques can measure the absolute amounts of the various plutonium isotopes in many kinds of samples. The idea of expanding these measurements to all isotopes to determine the isotopic distribution of the plutonium has appealed to gamma-ray spectroscopists for many years.

Starting in the early 1970s, researchers developed several approaches, some of which are described in Refs. 1-5. The characteristics of the many kinds of samples found in plutonium processing plants make it impossible to find one method that is optimum for all sample types. Instead, the history of these nondestructive isotopic measurements shows that the method was often tailored to the specific sample type. Different methods have been developed Eor solutions vs solids, freshly separated samples (americium and uranium removed) vs aged ones, and low-burnup material vs high-burnup material. 
Before we discuss the principles of isotopic measurements, we will introduce some of the characteristics of plutonium spectra that influence the approach to isotopic measurements. We will describe useful spectral regions and then present the principles of spectral analysis for isotopic analysis.

Typical data collection hardware and caveats will be described, followed by details of data analysis methods. A description of several implemented systems then follows with examples of their accuracy and precision.

\section{PRELIMINARY CONSIDERATIONS}

\section{A. Plutonium Isotope Decay Characteristics}

Most plutonium samples contain the isotopes ${ }^{238} \mathrm{Pu},{ }^{239} \mathrm{Pu},{ }^{240} \mathrm{Pu},{ }^{241} \mathrm{Pu}$, and ${ }^{242} \mathrm{Pu}$. Americium-241, a decay product of ${ }^{241} \mathrm{Pu}$, is always present, as is ${ }^{237} \mathrm{U}$, another decay product. When considering the total heat output of a sample reasured by calorimetry, ${ }^{24 l}$ Am becomes important because of its relatively short half-life and high specific power. Table I lists some of the decay characteristics of these important isotopes.

\section{TABLE I}

DECAY CHARACTERISTICS FOR ISOTOPES USEFUL IN PLUTONIUM ISOTOPIC MEASUREMENTS

\begin{tabular}{|c|c|c|c|}
\hline Isotr & $\begin{array}{l}\text { Half-Life } \\
\left(\mathrm{yI}_{\mathrm{I}}\right)\end{array}$ & $\begin{array}{r}\text { Activity } \\
(\mathrm{dis} / \mathrm{s} \cdot \mathrm{g})\end{array}$ & $\begin{array}{l}\text { Specific Power } \\
\text { (mw/g Isotope) }\end{array}$ \\
\hline & $87.74 \pm 0.04$ & $6.3330 \times 10^{11}$ & $567.57 \pm 0.26$ \\
\hline & $24119 \pm 26$ & $2.2942 \times 10^{9}$ & $1.9288 \pm 0.0003$ \\
\hline & $6564 \pm 11$ & $8.3945 \times 10^{9}$ & $7.0824 \pm 0.0020$ \\
\hline & $14.348 \pm 0.022$ & $3.8244 \times 10^{12}$ & $3.412 \pm 0.002$ \\
\hline & $376300 \pm 900$ & $1.4522 \times 10^{8}$ & $0.1159 \pm 0.0003$ \\
\hline $\begin{array}{l}24 l_{\text {Am }} \\
237_{U}\end{array}$ & $\begin{array}{l}433.6 \pm 1.4 \\
6.75 \text { days }\end{array}$ & $\begin{array}{l}1.2655 \times 10^{11} \\
9.4080 \times 10^{7 a}\end{array}$ & $\begin{aligned} 114.20 & \pm 0.42 \\
& -\end{aligned}$ \\
\hline
\end{tabular}

\footnotetext{
${ }^{a}$ Plutonium-241- $237 \mathrm{v}$ equilibrium assumed (see Fig. 1). Alpha branching ratio of ${ }^{241}$ Pu assumed to be $2.46 \times 10^{-5}$.
} 


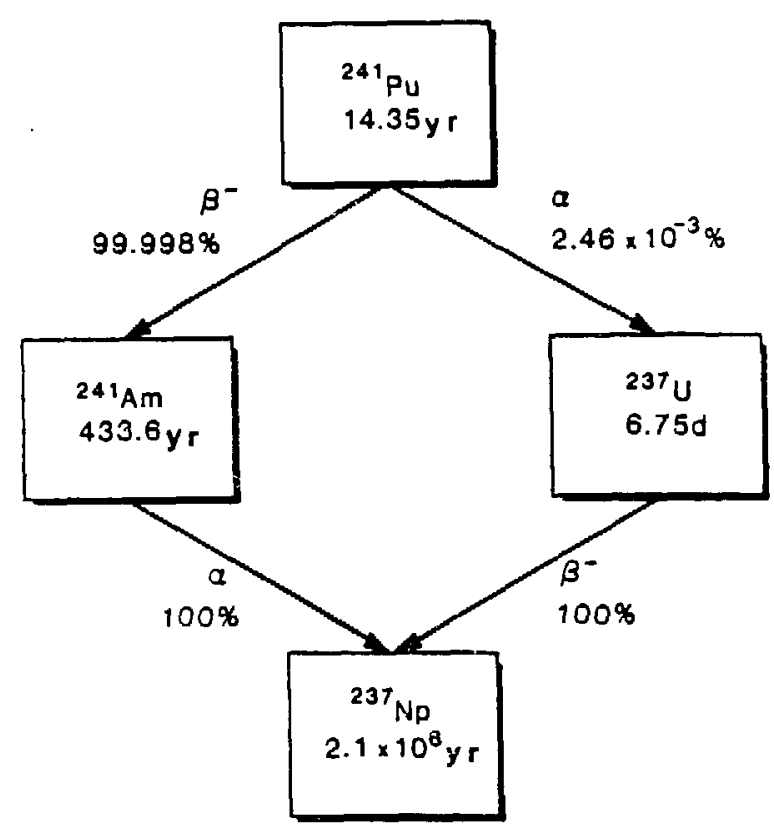

Fig. 1. Decay modes of ${ }^{241} \mathrm{Pu}$.

\section{B. 241 Pu Decay}

The decay characteristics of ${ }^{241} \mathrm{Pu}$ shown in Fig. 1 become important Eor plutonium isotopic measurements. The long half-life of its 241 Am daughter (relative to ${ }^{241} \mathrm{Pu}$ ) means that ${ }^{241}$ Am concentration continues to increase for decay times up to 75 years. Old plutonium samples often have very high ${ }^{241}$ An content, especially if a large amount of ${ }^{241}$ pu was initially present.

The short half-life of the ${ }^{237} \mathrm{u}$ daughter means that it rapidly comes into secular equilibrium ${ }^{6}$ with its ${ }^{241} \mathrm{Pu}$ parent. After about seven half-lives have elapsed, the decay rate of ${ }^{237} \mathrm{U}$ becomes the same as the decay rate of ${ }^{241} \mathrm{Pu}$. After that time, gamma rays from the decay of $237 \mathrm{U}$ can be used as a measure of the amount of ${ }^{241} \mathrm{Pu}$ in a sample. Because ${ }^{237} \mathrm{U}$ has several strong gamma rays, it becomes an important isotope for plutonium isotopic measurements. We will refer to samples where $237 \mathrm{G}$ is in secuiar equilibrium with ${ }^{241} \mathrm{Pu}$ as "241 ${ }^{24-}{ }^{237} \mathrm{v}$ equilibrium" or "aged. somples. About $99 \%$ of equilibrium is attained in 45 days after complete removal or separation of ${ }^{237} \mathrm{U}$ from a sample. We call samples where ${ }^{241} \mathrm{Pu}-{ }^{237} \mathrm{U}$ equilibrium does not exist "Ereshly separated." For those samples, ${ }^{237} \mathrm{U}$ cannot be used as a measure of ${ }^{241} \mathrm{Pu}$.

We also observe in Fig. I that both ${ }^{241} \mathrm{Am}$ and ${ }^{237} \mathrm{v}$ decay to the same isotope, ${ }^{237} \mathrm{~Np}$. Many of these decays populate the same excited states in ${ }^{237} \mathrm{~Np}$ and give rise to identical gamma rays. Thus, most of the useful $237 \mathrm{U}$ gamma rays have a contribution from the ${ }^{241} \mathrm{Am}$ in the sample. The amount of this interference depends upon the particular gamma ray and how long the $24 \mathrm{l}_{\text {Am }}$ has grown into the sample. Figure 2 shows the relative contributions for important ${ }^{237} \mathrm{U}$ gamma rays where it has been assumed that all ${ }^{237} \mathrm{U}$ and ${ }^{241}$ Am were removed from the sample at $t=0$. A correction should be made to ${ }^{241} \mathrm{Pu}^{237} \mathrm{U}$ peaks for their ${ }^{24 l}$ Am content. 


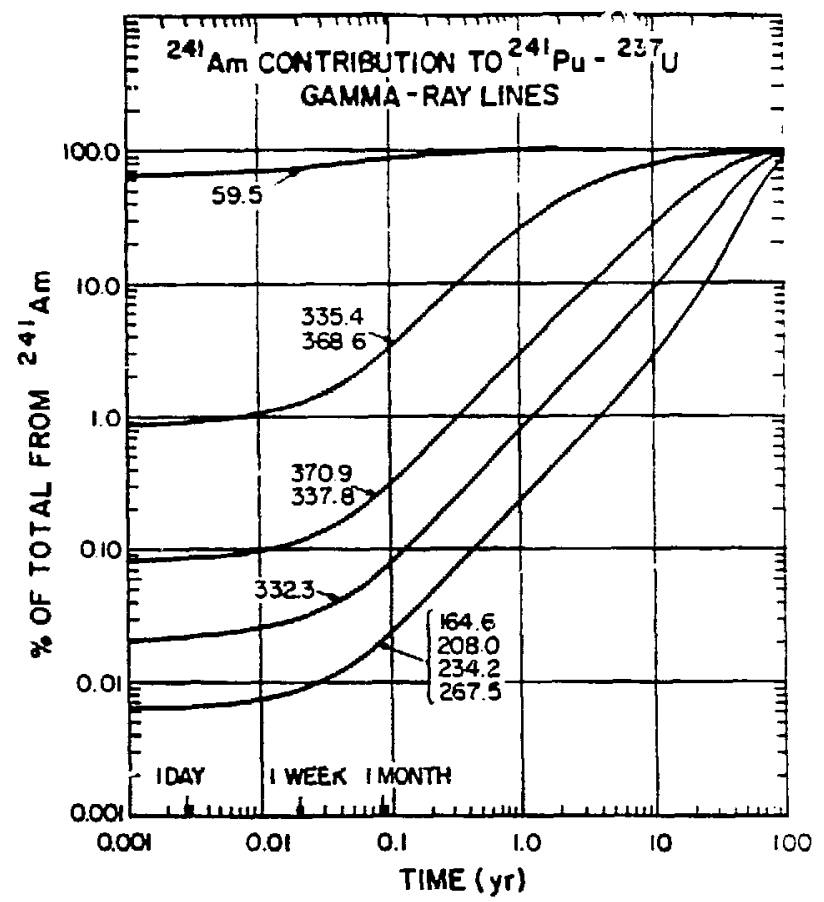

Fig. 2. Americium-241 contribution to gamma rays from the decay of $237_{\mathrm{U}}$. Legend is gamma-ray energies in keV. Ali uranium and americium assumed to be removed at $t=0$.

C. $\quad 242 \mathrm{Pu}$

Plutonium-242 has only a few gamma rays, similar in energy and branching ratio to those from ${ }^{240} \mathrm{Pu}$. However, its long half-life and low abundance make its detection by gamma-ray measurement impossible. Instead, experimenters resort to the use of empirical isotopic correlations ${ }^{7}$ to predict the ${ }^{242} \mathrm{Pu}$ content, given knowledge of the other isotopic fractions. This generally produces acceptable results for the small concentrations of ${ }^{242} \mathrm{pu}$ (typically $0.03 \%$ to $5 \%$ ) found in most plutonium.

\section{Spectral Interferences}

Many regions of the spectrum of gamma rays can contain interferences from gamma rays Erom other isotopes in the sample. Very-high-burnup samples will often have ${ }^{243} \mathrm{Am}$ and its ${ }^{239} \mathrm{~Np}$ daughter. Aged samples may have the ${ }^{233} \mathrm{Pu}$ daughter of ${ }^{237} \mathrm{~Np}$. Fission products can be present in some cases. One cannot list all the possible interferences here, but. it suffices to say that the spectroscopist should try to know the sample history in order to anticipate possible spectral interferences. 


\section{E. Applications}

The principal application of plutonium isotopic measurements is to support other nondestructive assay (NDA) methods to provide measurements of the total plutonium content of the sample. Calorimetry and neutron coincidence counting can utilize plutonium isotopic results.

Calorimetry uses the isotopic information to calculate the specific power of the sample, $\mathrm{P}(\mathrm{W} / \mathrm{g} \mathrm{Pu})$, from the measured isotopic fractions $\mathrm{f}_{i}$ and the known specific power for each isotope $k_{i}$ ( $w / g$ isotope). From the variables, the sample specific power is given by

$$
P=\sum_{i} E_{i} K_{i}
$$

where

$$
\mathrm{i}={ }^{238} \mathrm{Pu},{ }^{239} \mathrm{Pu},{ }^{240} \mathrm{Pu},{ }^{241} \mathrm{Pu},{ }^{242} \mathrm{Pu} \text {, and }{ }^{241} \mathrm{Am} .
$$

For neutron coincidence counting only the even isotopes-- ${ }^{238} \mathrm{Pu},{ }^{240} \mathrm{Pu}$, and ${ }^{242} \mathrm{Pu}-$-are important, with the measurement giving a value for the effective $\mathrm{g}{ }^{240} \mathrm{Pu}$ in the sample. The known isotopic composition is used to convert the effective $\mathrm{g}{ }^{240} \mathrm{Pu}$ into total plutoniun using the expression

$$
E_{240}\left(\text { eEE) }=2.49 \mathrm{E}_{238}+\mathrm{E}_{240}+1.57 \mathrm{E}_{242} .\right.
$$

The f's denote the isotopic Eraction of the subscripted isotope.

\section{SPECTRAL REGIONS USEFUL FOR ISOTOPIC MEASUREMENTS}

To fully understand the different methods developed for isotopic measurement of plutonium by gamma-ray spectroscopy, one must be familiar with the spectral features in the various regions of the gamma-ray spectrum from all types of samples. The energies and branching ratios used in the following tables come from the widely used work of Gunnink et al. ${ }^{8}$ The spectral regions discussed below follow those suggested in Ref. 8 and further discussed in the guide published by Lemming and Rakel. ${ }^{9}$ Different burnup, hence different isotopic distributions, and, especially, different ${ }^{241}$ Am concentrations can greatly affect the number and intensity of gamma rays appearing in the spectrum. Figures 3 and 4 show two examples, with Fig. 3 representing low 


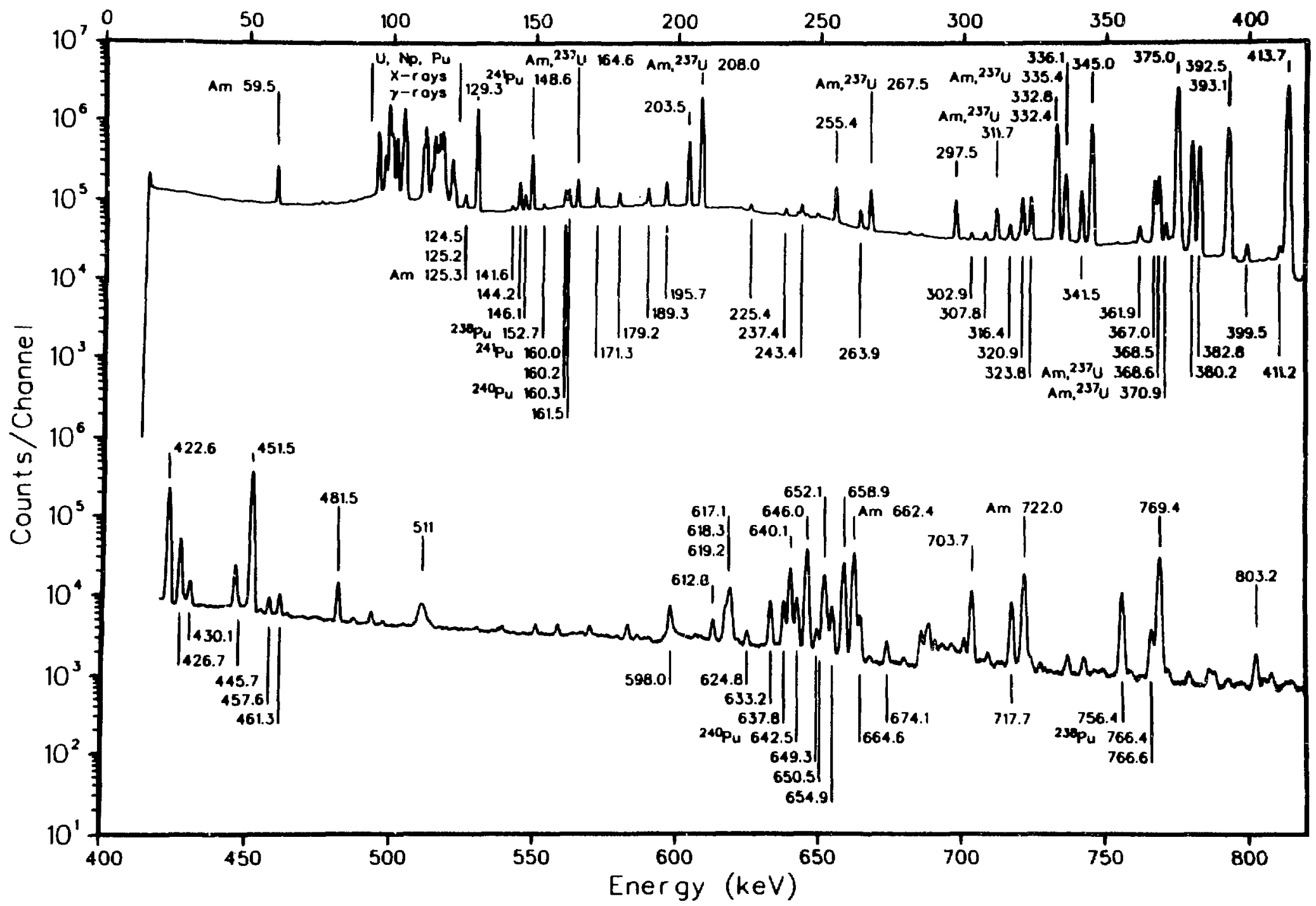

Fig. 3. Spectrum from $500 \mathrm{~g}$ of plutonium metal with isotopic composition (wt 8 ): 238. $0.0128 ; 239,93.828 ; 240,5.908 ; 241,0.2408 ; 242,0.028 ;$ and $241_{\mathrm{Am},} 630 \mu \mathrm{g} / \mathrm{g} \mathrm{Pu}$. Detector js an $11.7 \%$ relative efficiency coax with $1.75-k e v$ resolution at 1332 kev. Energ:es not labeled with a specific isotope are from $239 \mathrm{pu}$. 


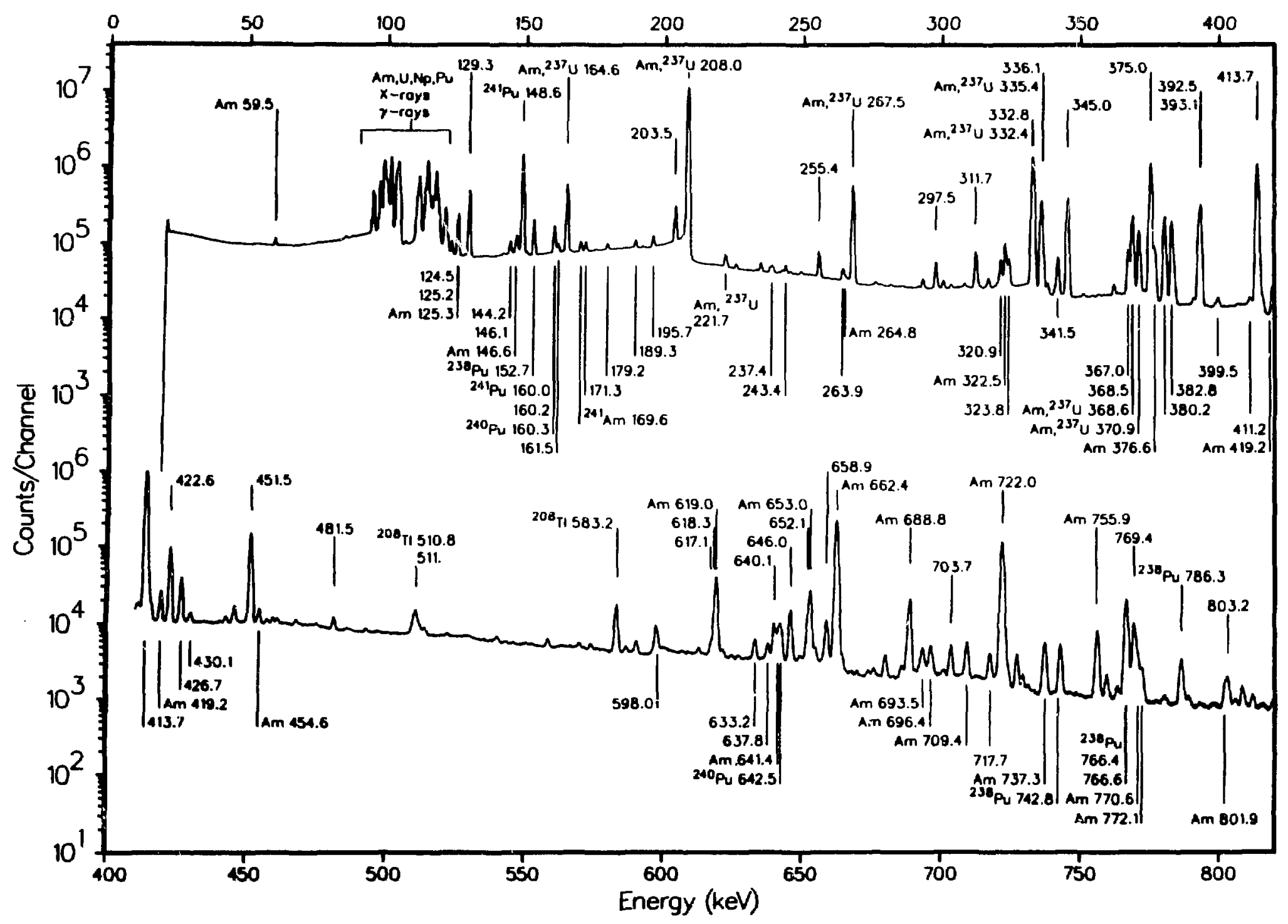

Fig. 4. Spectrum from $530 \mathrm{~g}$ plutonium as $\mathrm{PuO}_{2}$ with isotopic composition (wt\%): 238, $0.2028 ; 239,82.498 ; 240,13.758 ; 241,2.698 ; 242,0.768$; Am, $11800 \mu \mathrm{g} / \mathrm{g}$ Pu. Detector is a 10.28 relative efficiency coax with $1.65-\mathrm{keV}$ resolution at $1332 \mathrm{keV}$. Energies not labeled with a specific isotope are from $239 \mathrm{pu}$. 
burnup and low ${ }^{24 \mathrm{Am}}$ and $\mathrm{Fig} .4$ representing intermediate burnup and relatively high $24 \mathrm{Am}$. The discussion and figures for each spectral region attempt to illustrate reasonable extremes.

Table II lists most of the useful gamma rays for plutonium isotopic measurements with their activity in gamma rays per second per gram of isotope. We observe that the lower-energy gamma rays are more intense than those at higher energies. It is desirable to use these whenever possible, but experimental and sample considerations often make this impossible.

\section{A. $40-\mathrm{keV}$ Region}

This region has been used mainly for the anaiysis of freshly separated

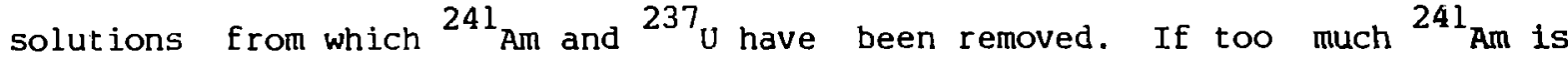
present, its $60-\mathrm{keV}$ gamma ray will overwhelm all other peaks in the region. making this region useless for isotopic measurements. Usually, this region can be use 3 for times up to about 15 to 30 days after a separation of americium and uranium. Figure 5 shows a typical spectrum from a high-burnup reprocessing plant solution ${ }^{10}$ and Table III lists peak energies and intensities. If it is accessible, this is the most useful region for ${ }^{238} \mathrm{Pu},{ }^{239} \mathrm{Pu}$, and ${ }^{240} \mathrm{Pu}$. Measurement of ${ }^{241} \mathrm{Pu}$ is usually obtained from its 148.6-kev gamma ray. Small contributions from ${ }^{241} \mathrm{Pu}$ and ${ }^{237} \mathrm{U}$ interfere with the main ${ }^{238} \mathrm{Pu}$ peak at $43.5 \mathrm{keV}$, the ${ }^{240} \mathrm{Pu}$ peak at $45.2 \mathrm{keV}$, and the ${ }^{239} \mathrm{Pu}$ peak at $51.6 \mathrm{keV}$.

Several experimenters have used this region for solution measurements. Gunnink et al. ${ }^{11}$ and Russo et al. ${ }^{10}$ have measured freshly separated reprocessing plant solutions; Umezawa et al. ${ }^{12}$ and Bubernak $^{13}$ have applied these measurements to samples prepared in an analytical laboratory. Li et al. 14 have also used this region for submilligram-sized solid samples with modest $241_{\text {Am content. }}$ cons

We have not yet discussed data analysis techniques, but we will mention them in general reference to the different methods used to analyze data in the 40-kev region. The next subsection will describe the analysis methods in more detail.

Gunnink $^{11}$ uses absolute counting techniques employing calibration with known solution standards. Umezawa et al. ${ }^{12}$ also use absolute counting with a calibrated detector, whereas Bubernak $^{13}$ calibrates with samples of known isotopic composition. Russo et. al. ${ }^{10}$ and $\mathrm{Li}$ et al. ${ }^{14}$ measure isotopic 
TABLE II

USEFUL GAMMA RAYS IN VARIOUS ENERGY REGIONS

\begin{tabular}{|c|c|c|c|c|c|c|c|c|c|c|}
\hline \multirow{2}{*}{$\begin{array}{l}\text { Region } \\
\text { (kev) }\end{array}$} & \multicolumn{2}{|c|}{${ }^{238} \mathrm{Pu}$} & \multicolumn{2}{|c|}{${ }^{239} \mathrm{Pu}$} & \multicolumn{2}{|c|}{${ }^{240} \mathrm{Pu}$} & \multicolumn{2}{|r|}{${ }^{24} 1_{\mathrm{PU}}$} & \multicolumn{2}{|c|}{$241_{\text {Ann }}$} \\
\hline & (kev) & $(x / s \cdot q)$ & (kev) & $(x(s \cdot g)$ & $(\mathrm{keV})$ & $(r / s \cdot g)$ & $(\underline{\mathrm{keV}})$ & $(r / s \cdot g)$ & (kev) & $(Y / s \cdot g)$ \\
\hline $40-60$ & 43.48 & $2.49 \times 10^{8}$ & 51.6 .3 & $6.19 \times 10^{5}$ & 45.23 & $3.80 \times 10^{6}$ & & 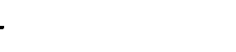 & 59.54 & $4.54 \times 10^{10}$ \\
\hline $90-105^{a}$ & 49.86 & $4.59 \times 10^{7}$ & 98.78 & $2.80 \times 10^{4}$ & 104.24 & $5.86 \times 10^{5}$ & 103.68 & $3.96 \times 10^{6}$ & $\begin{array}{r}98.95 \\
102.97\end{array}$ & $\begin{array}{l}2.57 \times 10^{7} \\
2.47 \times 10^{7}\end{array}$ \\
\hline $120-450$ & 152.68 & $6.05 \times 10^{6}$ & $\begin{array}{l}129.29 \\
203.54 \\
345.01 \\
375.04 \\
413.71\end{array}$ & $\begin{array}{l}1.44 \times 10^{5} \\
1.28 \times 10^{4} \\
1.28 \times 10^{4} \\
3.60 \times 10^{4} \\
3.42 \times 10^{4}\end{array}$ & 160.28 & $3.38 \times 10^{4}$ & $\begin{array}{l}148.57 \\
164.53 \\
208.00 \\
332.35 \\
370.93\end{array}$ & $\begin{array}{l}7.15 \times 10^{6} \\
1.73 \times 10^{6} \mathrm{~b} \\
2.04 \times 10^{7} \mathrm{~b} \\
1.14 \times 10^{6} \mathrm{~b} \\
1.04 \times 10^{5} \mathrm{~b}\end{array}$ & $\begin{array}{l}125.29 \\
335.40\end{array}$ & $\begin{array}{l}5.16 \times 10^{6} \\
6.28 \times 10^{5}\end{array}$ \\
\hline $450-300$ & 766.41 & $1.39 \times 10^{5}$ & $\begin{array}{l}645.97 \\
717.72\end{array}$ & $\begin{array}{l}3.42 \times 10^{2} \\
6.29 \times 10^{1}\end{array}$ & 642.48 & $1.05 \times 10^{3}$ & & - & $\begin{array}{l}662.42 \\
721.99\end{array}$ & $\begin{array}{l}4.61 \times 10^{5} \\
2.18 \times 10^{5}\end{array}$ \\
\hline
\end{tabular}

aThere are also intense $x$ rays in this region arising from all the 1sotopes. Although they are not listed here, they may be used for isotopic measurements under certrin conditions. See Table IV for intensities.

burar: 1um-237 daughter of $241_{\text {Pu with }} 241_{\mathrm{Pu}} 237_{\mathrm{U}}$ equiliter1um. 


\section{0-keV Region}

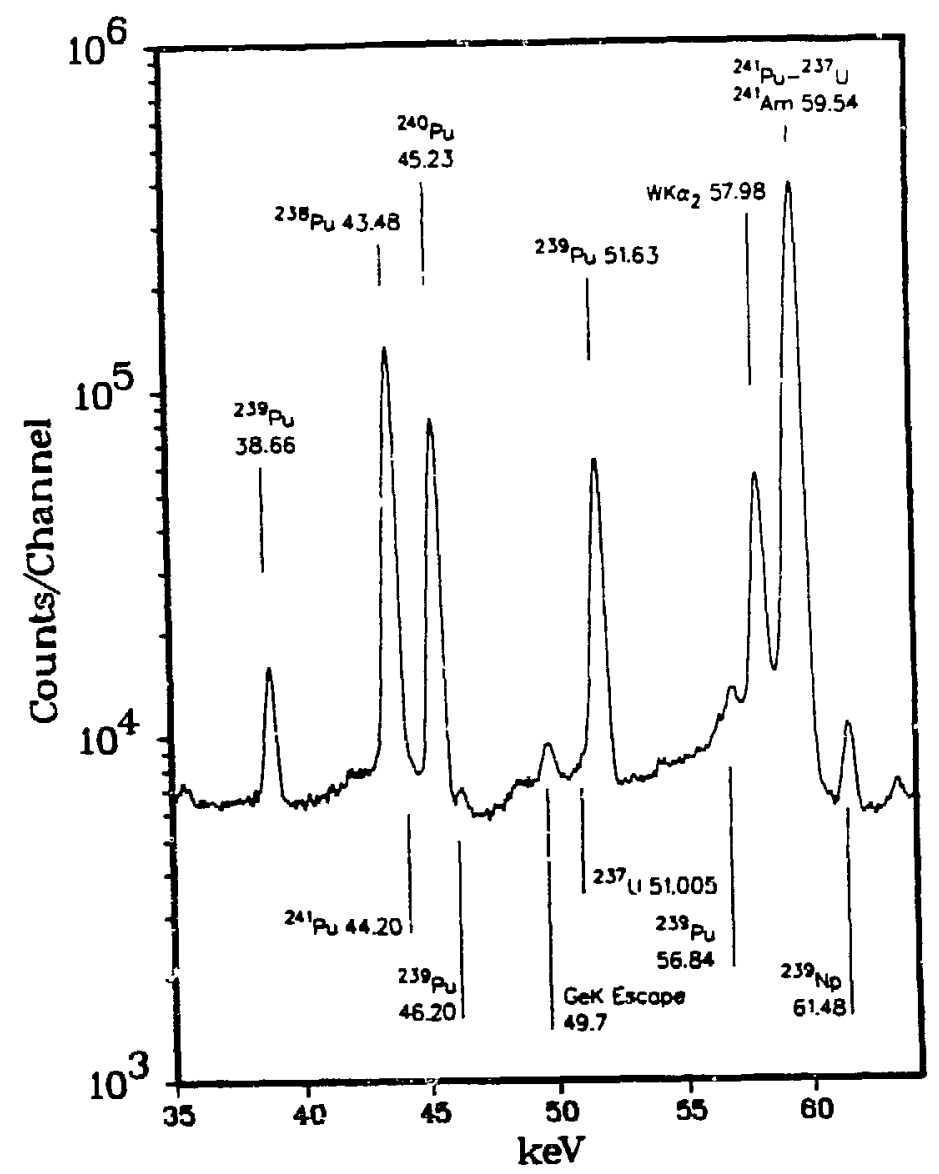

Fig. 5. Freshly separated $185-\mathrm{g} / \mathrm{l}$ solution of plutonium in nitric acid. Isotopic composition (wtz): 238, 0.6498; 239, 67.018; 240, 21.80\%; 241, 8.118: 242, 2.448. The wko2 $x$ ray arises Erom shielding around the detector (Ref. 10).

ratios, making the measurements independent of calibration standards. This is necessary for the measurements of $\mathrm{Li} \in \mathrm{t}$ al. ${ }^{14}$ because the samples do not have reproducible geometry.

\section{B. $100-\mathrm{keV}$ Region}

This region is the most complex of all regions of the gamma-ray spectrum of plutonium. Table IV tabulates 14 gamma rays and $x$ rays. The uranium $x$ rays arise from plutonium decay and can be used to measure the amount of some plutonium isotopes. Neptunium $x$ rays arise from the decay of ${ }^{241} \mathrm{Am}$ and $237 \mathrm{U}$, 
TABLE III

PEAK ENERGIES AND INTENSITIES IN 40-keV REGION 8

\begin{tabular}{|c|c|c|c|c|}
\hline Isotope & $\begin{array}{l}\text { Energy } \\
\text { (kev) }\end{array}$ & $\begin{array}{l}\text { Branching Ratio } \\
\text { (photons/dis) }\end{array}$ & $\begin{array}{c}\text { Error } \\
(\xi) \\
\end{array}$ & $\begin{array}{c}\text { Activity } \\
(\text { photons } / s \cdot q)\end{array}$ \\
\hline $239 \mathrm{Pu}$ & 38.664 & $1.050 E-04$ & 1.00 & $2.4089 E+05$ \\
\hline & 40.410 & $1.620 E-06$ & 10.00 & $3.7165 E+03$ \\
\hline & 42.060 & $1.650 E-06$ & 3.00 & $3.7854 E+03$ \\
\hline & 43.430 & $5.904 E-09$ & 7.00 & $2.2579 E+04$ \\
\hline & 43.477 & $3.930 E-04$ & 0.30 & $2.4889 E+08$ \\
\hline $24 l_{\mathrm{Pu}}$ & 44.200 & $4.180 E-08$ & & $1.5986 E+05$ \\
\hline & 44.860 & $8.360 E-09$ & & $3.1972 E+04$ \\
\hline & 45.232 & $4.530 E-04$ & 0.20 & $3.8039 E+06$ \\
\hline & 46.210 & $7.370 E-06$ & 10.00 & $1.6908 E+04$ \\
\hline & 46.690 & $5.800 \mathrm{E}-07$ & 6.00 & $1.3306 E+03$ \\
\hline & 51.005 & $8.364 E-08$ & 2.00 & $3.1987 E+05$ \\
\hline Pu & 51.629 & $2.700 E-04$ & 0.20 & $6.1942 E+05$ \\
\hline & 54.040 & $2.000 \mathrm{E}-06$ & 1.40 & $4.5883 E+03$ \\
\hline & 56.320 & $2.500 E-08$ & & $9.5610 \mathrm{E}+04$ \\
\hline $\mathrm{Pu}$ & 56.760 & $9.750 \mathrm{E}-09$ & & $3.7288 E+04$ \\
\hline & 56.838 & $1.130 E-05$ & 1.00 & $2.5924 E+04$ \\
\hline & 59.536 & $8.487 E-06$ & 0.20 & $3.2458 E+07$ \\
\hline & 59.536 & $3.590 \mathrm{E}-01$ & & $4.5432 E+10$ \\
\hline $237 \mathrm{u}^{\mathrm{a}}$ & 64.832 & $3.198 E-07$ & 0.50 & $1.2230 E+06$ \\
\hline
\end{tabular}

aranium-237 activity computed assuming ${ }^{241} \mathrm{Pu}^{237} \mathrm{U}$ equilibrium. Uranium-237 branching ratio includes $2.46 \times 10^{-5241} \mathrm{Pu}$ alpha branch to $237 \mathrm{u}$. 
TABLE IV

PEAK ENERGTES AND INTENSITIES IN 100-keV REGION 8

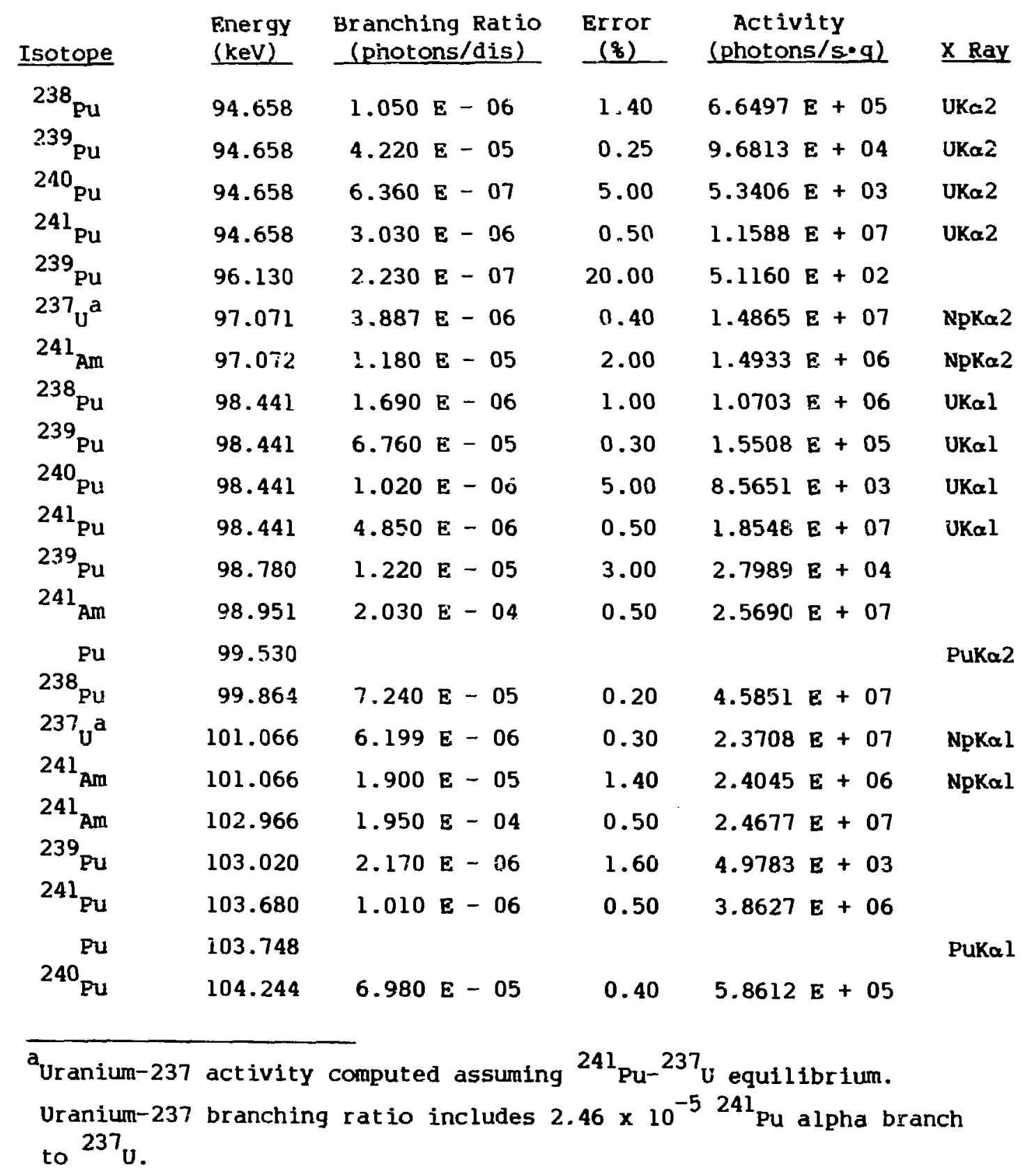


whereas the plutonium $x$ rays appear in larger or more concentrated samples Erom gamma-ray and alpha-particle-induced $x$-ray fluorescence. Gamma rays are present from all the principal plutonium 1sotopes. This is the only region where these conditions exist. Branching intensities are generally larger than those at higher energies ( ${ }^{239} \mathrm{Pu}$ is an exception) and smaller than those in the 40-keV region ( ${ }^{241} \mathrm{Pu}$ is the exception).

Figure 6 shows the strong, overlapping, interfering nature of the spectrum in this region. For low-burnup solutions, represented at the bottom of Fig. 6, the entire isotopic distribution may be determined. ${ }^{4}$ The complexity of the region requires peak-fitting or response-function ${ }^{4,15}$ analysis. The special case of low-burnup $\mathrm{PuO}_{2}$ has also been treated by response-function methods. High-burnup solutions have also been analyzed using response-function methods in this region, ${ }^{11}$ but in general, this is more difficult. The increased activity of high-burnup and high-concentration solutions gives rise to a plutonium fluorescent $x$ ray at $103.75 \mathrm{keV}$ that lies very close to the 104.24-kev ${ }^{240} \mathrm{Pu}$ gamma ray, as well as to a plutonium $x$ ray at $99.53 \mathrm{keV}$ that interferes with the $99.86-\mathrm{keV}{ }^{238} \mathrm{Pu}$ gamma. The different intrinsic line shape of $x$ rays as opposed to gamma rays also must be considered in the analysis of this region by response-function methods. We will discuss this later.

\section{125-keV Region}

This region is used primarily for measurement of ${ }^{241} \mathrm{Am}$ and ${ }^{239} \mathrm{Pu}$ with gamma rays at 125.29 and $129.29 \mathrm{keV}$ respectively. Plutonium-239 lines at 125.21 and $124.51 \mathrm{keV}$ strongly interfere with the $125.29-\mathrm{keV}{ }^{241}$ Am gamma line. It is difficult to obtain the ${ }^{241}$ Am peak area for ${ }^{241} \mathrm{Am}$ concentrations below a few hundred $\mu \mathrm{g} / \mathrm{g} \mathrm{Pu}$. At an americium concentration of $500 \mu \mathrm{g} / \mathrm{g} \mathrm{Pu}$, the ${ }^{239} \mathrm{Pu}$ interferences contribute over $50 \%$ of the peak area between 124.5 and $125.3 \mathrm{keV}$. For an americium concentration of $5000 \mu \mathrm{g} / \mathrm{g} \mathrm{Pu}$, over $90 \%$ of the intensity in this region is from ${ }^{241} \mathrm{Am}$. The ${ }^{239} \mathrm{Pu}$ interferences can be removed by peak fitting ${ }^{16}$ or stripping. 17 Many measurements use absorbers or filters (see sec. V.C) to reduce the count rate of lower-energy gamma rays in. the spectrum. These absorbers also affect the count rate in the $125-k e v$ re- $^{-}$ gion. A useful filter thickness of $0.15 \mathrm{~cm}(0.06 \mathrm{in.})$ of cadmium has a transmission of $35 \%$ at $123.5 \mathrm{keV}$, giving a factor of 3 reduction in the $125-\mathrm{keV}$ count rate. 


\section{0-keV Region}

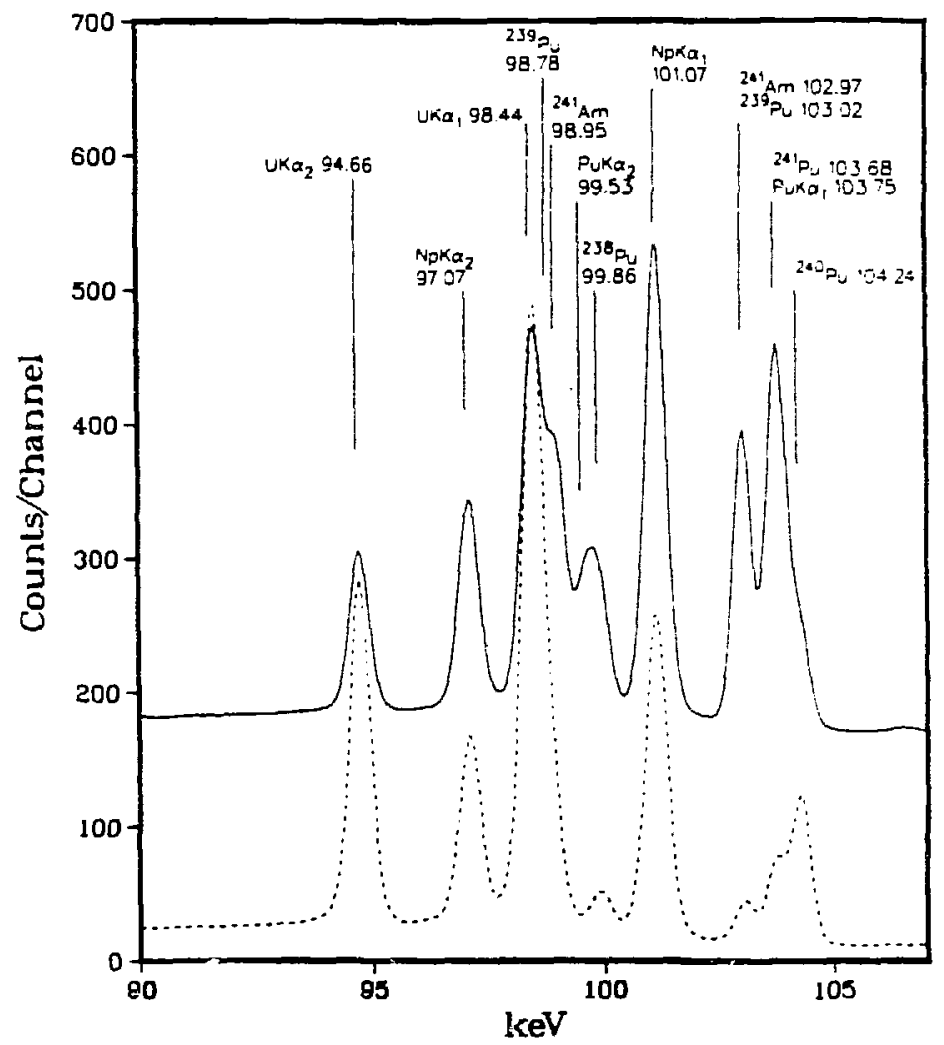

Fig. 6. Top (solid line)--530 g plutonium as $\mathrm{PuO}_{2}$ counted with a 200-min ${ }^{2} \times 10-$-nu-deep planar HpGe detector with resolution of $490 \mathrm{eV}$ at $122 \mathrm{keV}$. Isotopic composition (wt\%): 238, $0.3028 ; 239,82.498 ; 240,13.758 ; 241,2.698$; 242, $0.768 ; 24 l_{\mathrm{Am}, 2} 11800 \mu \mathrm{g} / \mathrm{g} \mathrm{Pu}$. The units of the linear counts scale are arbitrary.

Bottum (dashed line)-- $10 \mathrm{ml}$ of $20 \mathrm{~g} \mathrm{Pu} / \mathrm{l}$ solution in $1 \mathrm{H}^{\mathrm{HNO}} 3$ counted with same detector as above. Isotopic composition ( $w t z)$ ) 238, 0.027\%; $239,91.65 \% ; 240,7.688 ; 241,0.532 \% ; 242,0.12 \%$;

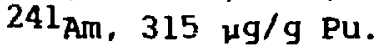

The ${ }^{241}$ An gamma ray at $125.29 \mathrm{keV}$ is about 10 times weaker than the ${ }^{241}$ Am gamma rays in the $100-k e v$ region.

In the Table $v$ listing of peak energies and intensities in this region, plutonium fluorescent $\mathrm{KB} \times$ rays in the $120-$ to $121-\mathrm{keV}$ range are omitted. In the plots of Fig. 7, we see that these further complicate analysis in this region by making it difficult to find a place to establish backgrounds below 
TABLE V

PEAK ENERGIES AND INTENSITIES IN $125-\mathrm{keV}$ REGION 8

\begin{tabular}{|c|c|c|c|c|}
\hline Isotope & $\begin{array}{l}\text { Energy } \\
\text { (keV) }\end{array}$ & $\begin{array}{l}\text { Branching Ratio } \\
\text { (photons/dis) }\end{array}$ & $\begin{array}{l}\text { Error } \\
(\%) \\
\end{array}$ & $\begin{array}{c}\text { Activity } \\
\text { (photons } / s \cdot g)\end{array}$ \\
\hline $239 \mathrm{Pu}$ & 119.708 & $3.000 E-07$ & 2.00 & $6.8825 E+02$ \\
\hline${ }^{241} \mathrm{Pu}$ & 121.200 & $6.850 E-09$ & & $2.6197 E+04$ \\
\hline $241_{\text {Am }}$ & 122.994 & $1.000 E-05$ & 0.80 & $1.2655 E+06$ \\
\hline${ }^{239} \mathrm{Pu}$ & 123.620 & $1.970 E-07$ & 6.00 & $4.5195 E+02$ \\
\hline & 124.510 & $6.130 E-07$ & 3.00 & $1.4063 E+03$ \\
\hline & 125.210 & $7.110 \mathrm{E}-07$ & 2.00 & $1.6311 E+03$ \\
\hline $241_{A m}$ & 125.292 & $4.080 E-05$ & 0.50 & $5.1633 E+06$ \\
\hline 2 & 129.294 & $6.260 E-05$ & 0.20 & $1.4361 E+05$ \\
\hline
\end{tabular}

$124.5 \mathrm{keV}$. Higher-burnup material (top of Fig. 7) generally has a stronger ${ }^{241}$ Am peak but a weaker ${ }^{239} \mathrm{Pu}$ peak than does low-burnup material. For highburnup samples, not only is the ${ }^{239} \mathrm{Pu}$ peak at $129.29 \mathrm{keV}$ weaker because of less ${ }^{239} \mathrm{pu}$ in the sample, but the background continuum under the peak is usually higher because of stronger ${ }^{241} \mathrm{Pu}$ and ${ }^{237} \mathrm{U}$ gamma rays at higher energies.

\section{148-keV Reqion}

The two most important peaks in this region are the $148.56-\mathrm{keV}{ }^{24 l_{\mathrm{Pu}}}$ peak and the $152.68-\mathrm{keV}{ }^{238} \mathrm{pu}$ peak. The $148.56-\mathrm{keV}$ peak is the only useful gamma ray directly from ${ }^{241} \mathrm{Pu}$ outside of the complex 100-kev range. Likewise the $152.58-\mathrm{kel}{ }^{238} \mathrm{Pu}$ peak, although weak, is still the most widely used gamuna ray from this isotope above $100 \mathrm{keV}$. Measurements can also use the 144.21 - and $143.35-\mathrm{keV}{ }^{239} \mathrm{Pu}$ lines, which have an interference from the $143.76-\mathrm{keV}{ }^{235} \mathrm{u}$ line from samples containing ${ }^{235} \mathrm{U}$. Americium-24l peaks at 146.56 and $150.11 \mathrm{keV}$ complicate window settings and background determination for methods that use simple region-of-interest (ROI) summation for peak areas. An additional interference can arise in systems that use a ${ }^{109} \mathrm{Cd}$ reference source for absolute measurement purposes. ${ }^{10.11}$ Here, the 88.04-kev ${ }^{109} \mathrm{Cd}$ gamma ray will sum with the $59.54-\mathrm{keV}{ }^{241}$ Am gamma ray to produce a pileup peak at $147.6 \mathrm{keV}$. Other interferences from summing can affect the 152.68 -keV

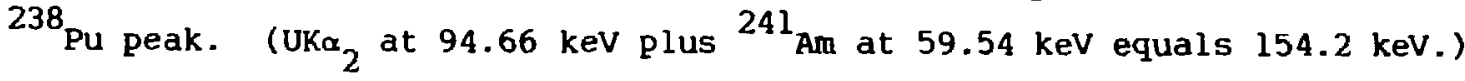




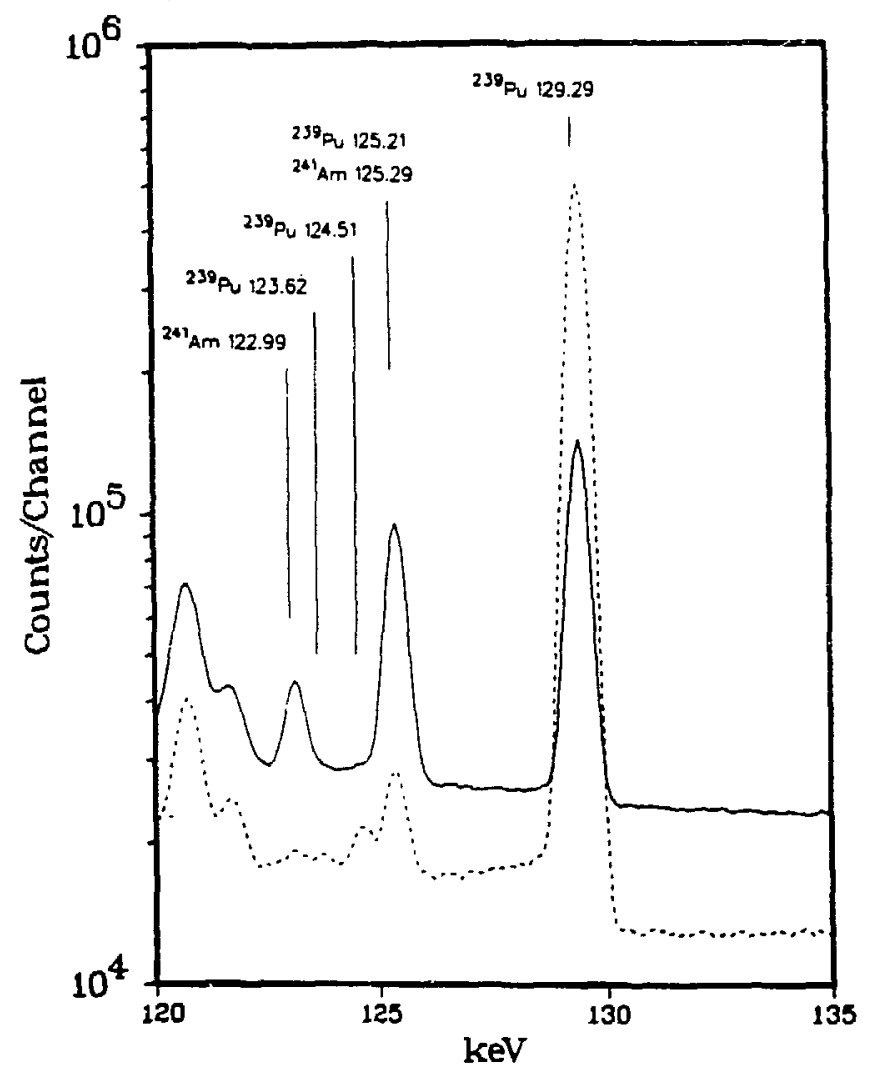

Fig. 7. Top (solid line)--PuO 2 counted with a $200-\mathrm{mm}^{2}$ by 10-mm-deep planar HpGe detector with resolution of $490 \mathrm{eV}$ at $122 \mathrm{keV}$. Isotopic composition (wtq): 238, 0.378\%; 239, 78.898; 240, 18.28\%; 241, 4.428; 242, $1.048 ; 241_{\text {Ara, }} 14300 \mu g / g \mathrm{Pu}$.

Bottom (dashed line)--same as top with isotopic composition (wt $)$ ): 238, 0.016\%; 239 . $93.518 ; 240,6.158 ; 241,0.2788 ; 242,0.0398$; $24 \mathrm{I}_{\mathrm{Am}}, 480 \mu \mathrm{g} / \mathrm{g} \mathrm{Pu}$.

The weak $153-k e v{ }^{238} \mathrm{pu}$ peak on a high background continuum generally yields poor precision for low-burnup $\left(0.01\right.$ wt\& $\left.{ }^{238} \mathrm{pu}\right)$ material. This precision can be as poor as 10\%, one relative standard deviation (RSD), for typical measurements. Also, for this peak, a branching ratio bias of about 2.58 is widely recognized. The accepted branching ratio is about 2.58 lower than the values in Table VI. Reference 18 discusses branching ratio biases in other energy regions. Figure 8 gives a plot of the peaks in this region from highand low-burnup material. 
TABLE VI

PEAK ENERGIES AND INTENSITIES IN 148-keV REGTON 8

\begin{tabular}{|c|c|c|c|c|}
\hline Isotope & $\begin{array}{l}\text { Energy } \\
\text { (kev) }\end{array}$ & $\begin{array}{l}\text { Branching Ratio } \\
\text { (photons/dis) }\end{array}$ & $\begin{array}{l}\text { Error } \\
(\%) \\
\end{array}$ & $\begin{array}{c}\text { Activity } \\
(\text { photons } / s \cdot g) \\
\end{array}$ \\
\hline${ }^{239} \mathrm{Pu}$ & 141.657 & $3.200 E-07$ & 2.00 & $7.3413 E+02$ \\
\hline & 143.350 & $1.730 E-07$ & 4.00 & $3.9689 E+02$ \\
\hline & 144.211 & $2.830 E-06$ & 0.60 & $6.4925 E+03$ \\
\hline & 146.077 & $1.190 \mathrm{E}-06$ & 0.60 & $2.7300 E+03$ \\
\hline & i 46.557 & $4.610 E-06$ & 1.00 & $5.8340 E+05$ \\
\hline & 148.567 & $1.870 E-06$ & 0.30 & $7.1516 E+06$ \\
\hline & 150.110 & $7.400 E-07$ & 2.00 & $9.3648 E+04$ \\
\hline${ }^{238} \mathrm{Pu}$ & 152.680 & $9.560 E-06$ & 0.50 & $6.0544 E+06$ \\
\hline
\end{tabular}

\section{E. $160-\mathrm{keV}$ Region}

For a single-detector system not using the 100- or 40-kev regions, the $160-\mathrm{keV}$ region is generally the only choice for measuring ${ }^{240} \mathrm{Pu}$. The ${ }^{240} \mathrm{Pu}$

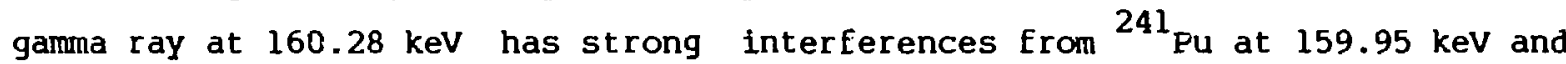
${ }^{239} \mathrm{Pu}$ at $160.19 \mathrm{keV}$. This three-peak complex (Fig. 9) is only partially resolved from the $161.45-\mathrm{keV}{ }^{239} \mathrm{Pu}$ line. Peak-Eitting, peak-stripping, or response-function methods must be used to isolate the ${ }^{240} \mathrm{Pu}$ intensity. Even so, its statistical precision is seldom better than $\sim 28$ RSD.

Also, as burnup increases, the fraction of the 160-kev complex contributed by ${ }^{240} \mathrm{Pu}$ decreases even though the entire complex increases in intensity. Using the branching ratio data of Table VII, we illustrate in Table VIII how the relative fraction of ${ }^{240} \mathrm{pu}$ in the $160-\mathrm{keV}$ complex decreases from almost $70 \%$ for $6 \%{ }^{240} \mathrm{Pu}$ to about $25 \%$ for material with $20 \%$ $240 \mathrm{Pu}$. This occurs because the ${ }^{241} \mathrm{Pu}$ interference increases more rapidly than ${ }^{240} \mathrm{Pu}$ as burnup increases.

The 164.58-keV peak arises from the ${ }^{237} \mathrm{U}$ daughter of ${ }^{241} \mathrm{pu}$; thus we can use it for ${ }^{241} \mathrm{Pu}$ measurements only after equilibrium has been attained. It must also have a correction for its $241_{\mathrm{Am}}$ contribution. Suming of 


\section{8-keV Region}

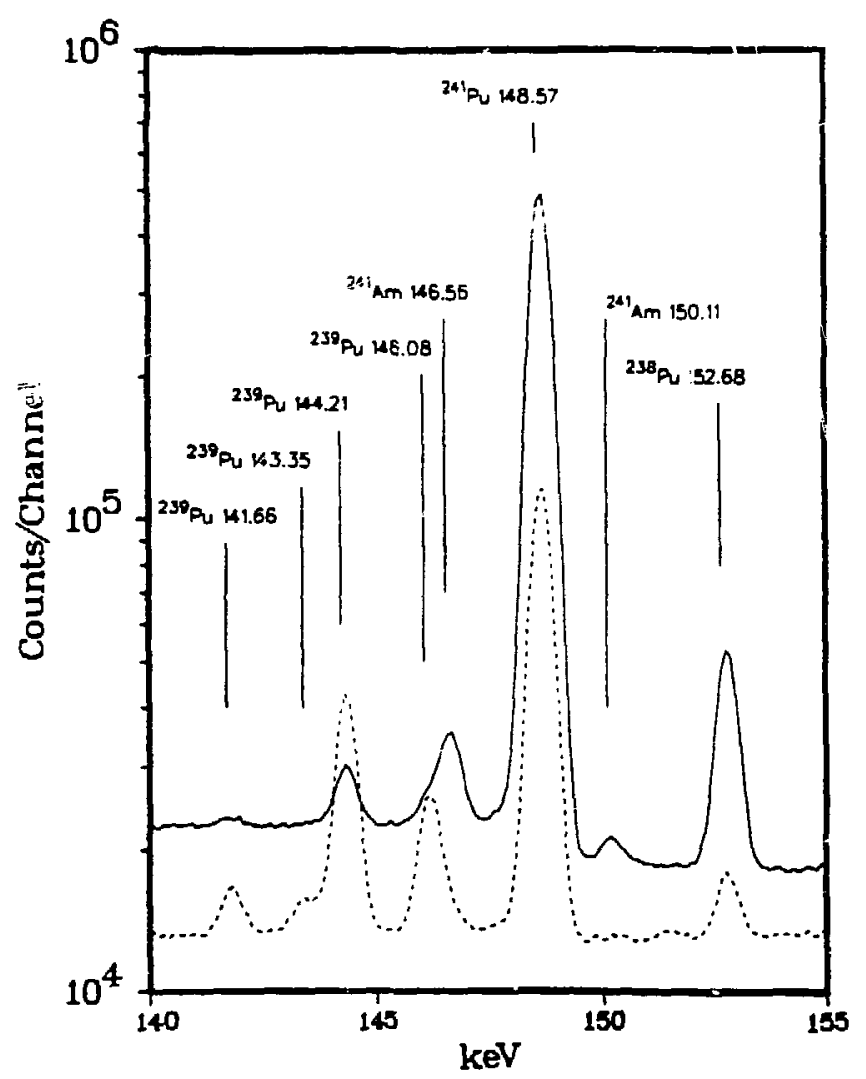

Fig. 8. Top (solid line)-- $\mathrm{PuO}_{2}$ counted with a $200-\mathrm{mm}^{2}$ by 10-mm-deep planar HpGe detector with resolution of $490 \mathrm{eV}$ at $122 \mathrm{keV}$. Isotopic composition (wtz): 238, $0.378 \%$; 239, 78.89\%; $240,15.288 ; 241,4.428 ; 242,1.048 ; 241_{\mathrm{Am}}$, $14300 \mu \mathrm{g} / \mathrm{g} \mathrm{Pu}$.

Botton (dashed iine)--same as top with isotopic composition (wtz): 238, 0.016\%; 239, 93.518; $240,6.158 ; 241,0.288 ; 242,0.0398 ; 241_{\mathrm{Am}}$, $480 \mu g / g$ Pu.

$x$ rays and gamma rays in the $100-k e v$ region with the $59.5-k e v{ }^{241}$ Am line can produce interferences under the 160-kev complex. The proper choice of filters can eliminate this interference. ${ }^{19}$ The ${ }^{235} \mathrm{U}$ gamma ray at $163.35 \mathrm{keV}$ can interfere with the ${ }^{241} \mathrm{Pu}-{ }^{237} \mathrm{U}$ line at $164.58 \mathrm{keV}$ for samples with appreciable ${ }^{235} \mathrm{U}$ content $\left({ }^{235} \mathrm{U} /{ }^{241} \mathrm{Pu}>1.5\right)$. 


\section{0-keV Region}

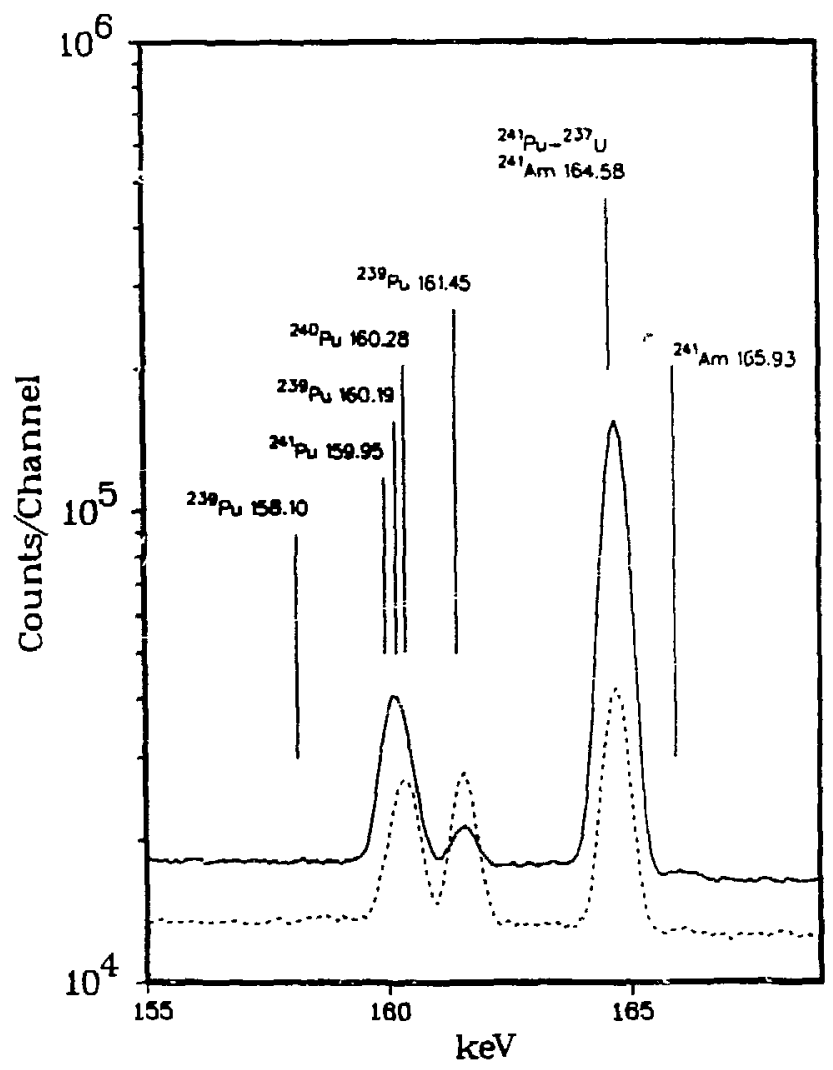

Fig. 9. Top (solid line)-- $\mathrm{PuO}_{2}$ counted with a 200-mm ${ }^{2}$ by 10-mm-deep planar HpGe detector with resolution of $490 \mathrm{ev}$ at $122 \mathrm{keV}$. Isotopic composition (wt\%): 238, 0.378\%; 239, 78.89\%; $240,15.288 ; 241,4.428 ; 242,1.048 ; 241_{\mathrm{Am}}$, $14300 \mu \mathrm{g} / \mathrm{g} \mathrm{Pu}$.

Bottom (dashed line)--same as top with isotopic composition (wts): 238, 0.0168; 239, 93.518; $240,6.158 ; 241,0.28$ \%; $242,0.0398 ; 241_{\mathrm{Am}}$, $480 \mu \mathrm{g} / \mathrm{g} \mathrm{Pu}$.

\section{F. 208-keV Region}

The strong ${ }^{24 \mathrm{l}_{\mathrm{Pu}-}}{ }^{237} \mathrm{U}$ line at $208.00 \mathrm{keV}$ dominates the region. Usually it is the rost intense line in the spectrum. It has a contribution from ${ }^{241}$ Am that becomes about $1 \%$ (relative) after 4 years. Because this in: is from $237 \mathrm{U}$, we can only use it for aged samples. Its strength and freedom from nearby interference make it a good peak to use for shape and energy calibrations for analysis methods using peak fitting or response functions. For 
PEAK ENERGIES AND INTENSITIES IN $160-\mathrm{keV}$ REGION8

\begin{tabular}{|c|c|c|c|c|}
\hline Isotope & $\begin{array}{r}\text { Energy } \\
\text { (keV) } \\
\end{array}$ & $\begin{array}{l}\text { Branching Ratio } \\
\text { (photons/ais) } \\
\end{array}$ & $\begin{array}{c}\text { Error } \\
(8) \\
\end{array}$ & $\begin{array}{c}\text { Activity } \\
\text { (photons } / s \cdot q)\end{array}$ \\
\hline${ }^{239} \mathrm{Pu}$ & 158.100 & $1.000 E-08$ & 10.00 & $2.2942 E+01$ \\
\hline & 159.955 & $6.740 E-08$ & & $2.5776 E+05$ \\
\hline & 160.190 & $6.200 E-08$ & 20.00 & $1.4224 E+02$ \\
\hline & 160.280 & $4.020 \mathrm{E}-06$ & 0.70 & $3.3756 E+04$ \\
\hline & 161.450 & $1.200 E-06$ & 0.40 & $2.7530 E+03$ \\
\hline & 164.580 & $4.526 E-07$ & 0.50 & $1.7311 E+06$ \\
\hline An & 164.580 & $6.670 E-07$ & 3.00 & $8.4410 E+04$ \\
\hline & 165.930 & $2.320 E-07$ & 4.00 & $2.9360 E+04$ \\
\hline
\end{tabular}

aranium-237 activity computed assuming $241 \mathrm{Pu}-{ }^{237} \mathrm{u}$ equilibrium. Uranium-237 branching ratio includes $2.46 \times 10^{-5241} \mathrm{Pu}$ alpha branch to $237 \mathrm{U}$.

TABLE VIII

COMPONENTS OF 160-keV COMPLEX

Isotope

239

240

241

239

240

241

239

240

241 wts

93.5

6.0

0.3

86.0

12.0

1.5

67.0

20.0

8.0
Percentage of $160-\mathrm{keV}$ Complex from Indicated Isotope

\section{$4.5 \%$}

69.18

26.48

$1.5 \%$

50.48

$4 \varepsilon .1 \%$

0.38

$24.6 \%$

75.18 
mixed oxides, ${ }^{235} \mathrm{u}$ peaks at $202 . \mathrm{l}$ and $205.3 \mathrm{keV}$ can interfere with the $203.54-\mathrm{keV}{ }^{239} \mathrm{Pu}$ line. The ${ }^{239} \mathrm{Pu} /{ }^{241} \mathrm{pu}$ ratio formed with the $203.54 / 208.00$ line pair gives best results for low-burnup material. For higher-burnup samples, the long tail Erom the very strong $208.00-\mathrm{keV} 237 \mathrm{U}$ peak hurts the weaker $203.54-\mathrm{keV}{ }^{239}$ Pu peak. High ${ }^{241}$ Am $(\sim 1 q)$ content can cause a few tenths percent interference with the 203.5-keV peak. Table IX lists and Fig. LO displays the parameters and spectrel features of this region.

\section{G. $332-\mathrm{keV}$ Region}

This region has contributions Erom ${ }^{241} \mathrm{Pu}-237 \mathrm{U},{ }^{241} \mathrm{Am}$, and ${ }^{239} \mathrm{Pu}$ as shown in Table $X$ and Eiy. 11. For high-burnup, aged material, the ratio of the $345.01-\mathrm{keV}{ }^{239} \mathrm{Pu}$ line to the $332.35-\mathrm{keV}{ }^{24 \mathrm{l}_{\mathrm{Pu}}}{ }^{237} \mathrm{U}$ is useful for the ${ }^{239} \mathrm{Pu} /$

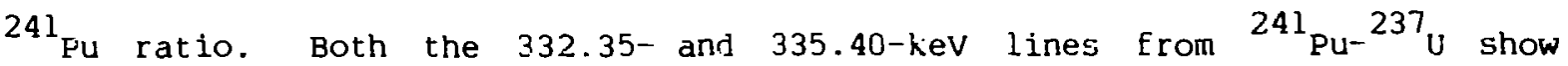
very close interferences from ${ }^{239} \mathrm{pu}$ peaks. In Fig. 11 the top plot of a verylow-burnup sample $\left(98 \%{ }^{239} \mathrm{Pu}\right)$ illustrates how close these two interferences are. For high-burnup material these ${ }^{239}$ pu interferences are fairly small. Table XI gives their relative nagnitude for different isotopic compositions. After the ${ }^{239} \mathrm{Pu}$ interferences are removed, the two peak complexes retain both

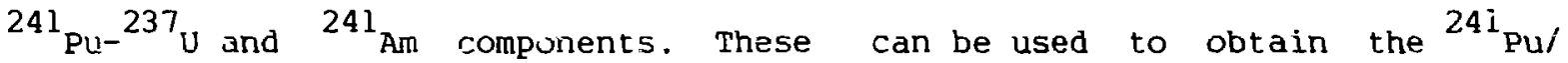
$241_{\text {Am }}$ ratio. ${ }^{3}$ possible analysis methods for this region are peak fitting. response functions, and stripping.

TABLE IX PEAK ENERGIES AND INTENSITIES IN 208-keV REGION 8

\begin{tabular}{|c|c|c|c|c|}
\hline Isutope & $\begin{array}{r}\text { Energy } \\
(\mathrm{keV}) \\
\end{array}$ & $\begin{array}{c}\text { Branching Ratio } \\
\text { (photons/dis) }\end{array}$ & $\begin{array}{c}\text { Error } \\
(8) \\
\end{array}$ & $\begin{array}{c}\text { Activity } \\
\text { (photons/s-q) }\end{array}$ \\
\hline & 203.537 & $5.600 E-06$ & 0.20 & $1.2847 E+04$ \\
\hline & 203.870 & $2.900 E-0 B$ & 6.00 & $3.6700 E+03$ \\
\hline $237 \mathrm{U}^{\mathrm{a}}$ & 206.000 & $5.338 E-06$ & 0.20 & $2.0415 E+07$ \\
\hline${ }^{241}$ Am & 208.000 & $7.910 E-06$ & 0.50 & $1.0010 E+06$ \\
\hline
\end{tabular}

$\mathrm{a}_{\text {Uranium-237 activity computed assuming }} 24 \mathrm{l}_{\mathrm{pu}-}{ }^{237} \mathrm{U}$ equilibrium. Uranium-237 branching ratio includes $2.46 \times 10^{-5241}$ Pu alpha branch to $237 \mathrm{u}$. 


\section{8-keV Region}

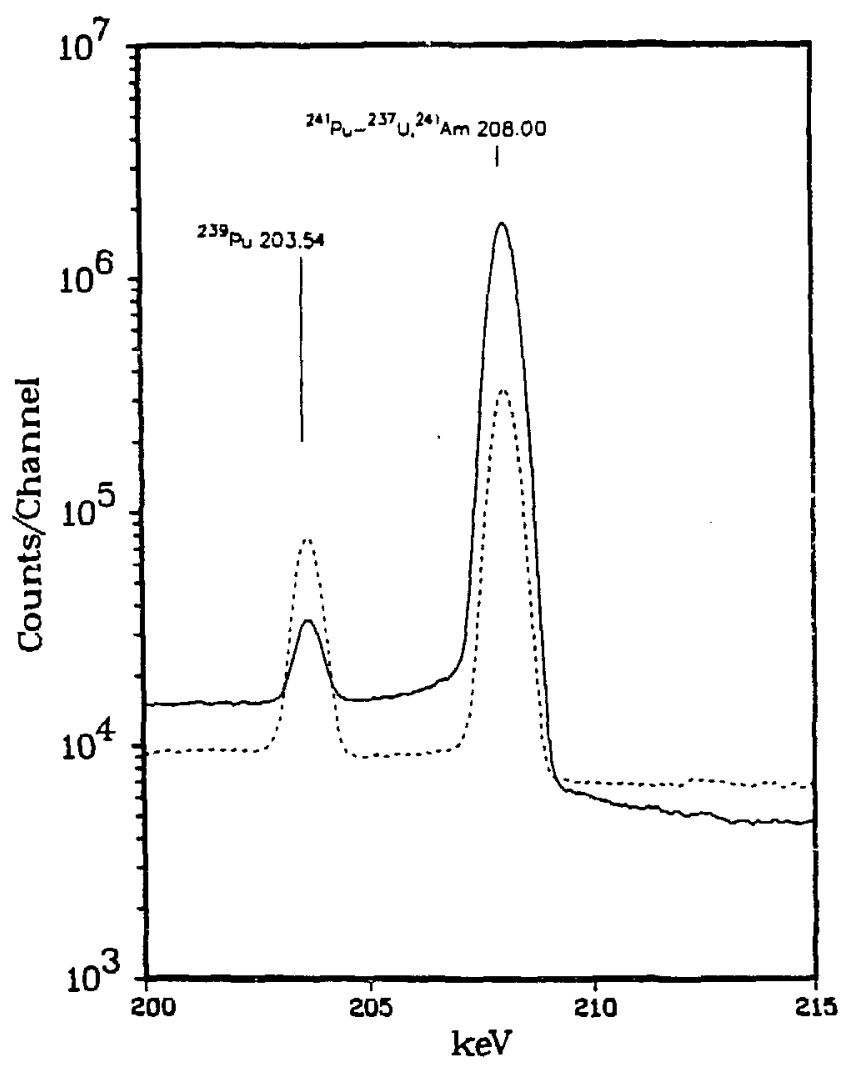

Fig. 10. Top (solid line)--PuO 2 counted with a $200-\mathrm{mm}^{2}$ by $10-\mathrm{mm}$-deep planar Hpge detector with resolution of 490 eV $\tau^{2} \cdot 122 \mathrm{keV}$. Isotopic composition ( $w t \%)$ : 238, 0.0378\%; 239, 78.898; $240,15.28 \% ; 241,4.428 ; 242,1.048 ; 241_{\mathrm{Am}}$, $14300 \mu \mathrm{g} / \mathrm{g}$ Pu.

Bottom (dashed line)---same as top with 1sotopic composition (wt\%): 238, 0.016\%; 239, 93.51\%; $240,6.15 \% ; 241,0.288 ; 242,0.0398 ; 241_{\mathrm{Am}}$, $480 \mu \mathrm{g} / \mathrm{g} \mathrm{Pu}$.

\section{H. 375-keV Region}

This region, shown in Fig. 12 and Table XII, has components from the same isotopes as the $332-\mathrm{keV}$ region, $241_{\mathrm{Pu}-}{ }^{237} \mathrm{U}, 241_{\mathrm{Am}}$, and ${ }^{239} \mathrm{Pu}$. For all isotopes except ${ }^{239} \mathrm{Pu}$, the branching ratios are lower than in the $332-\mathrm{keV}$ region, so the isotopic information will be less precise. The strong 375.04-keV ${ }^{239} \mathrm{Pu}$ peak is often used for relative efficiency determination. The ${ }^{241}$ Am interference at $376.59 \mathrm{keV}$ becomes bothersome for concentrations above a few thousand $\mu \mathrm{g} / \mathrm{g} \mathrm{Pu}$. 
TABLE $X$

PEAK ENERGIES AND INTENSITIES IN 332-keV REGION*

\begin{tabular}{|c|c|c|c|c|}
\hline Isotope & $\begin{array}{r}\text { Energy } \\
(\mathrm{keV}) \\
\end{array}$ & $\begin{array}{l}\text { Branching Ratio } \\
\text { (photons/dis) }\end{array}$ & $\begin{array}{l}\text { Error } \\
(\%) \\
\end{array}$ & $\begin{array}{c}\text { Activity } \\
(\text { photons } / s \cdot g)\end{array}$ \\
\hline $237 v^{a}$ & 332.354 & $2.977 E-07$ & 0.30 & $1.1384 E+06$ \\
\hline & 332.354 & $1.490 E-06$ & 0.30 & $1.8856 E+05$ \\
\hline${ }^{239} \mathrm{Pu}$ & 332.838 & $5.060 E-06$ & 0.20 & $1.1608 E+04$ \\
\hline $237 \mathrm{U}^{\mathrm{a}}$ & 335.405 & $2.386 E-08$ & 1.00 & $9.1258 E+04$ \\
\hline $241_{\text {AIn }}$ & 335.405 & $4.960 E-06$ & 0.30 & $6.2769 E+05$ \\
\hline & 336.107 & $1.134 E-06$ & 0.30 & $2.6016 E+03$ \\
\hline${ }^{241} \mathrm{Am}$ & 337.720 & $4.290 E-08$ & 5.00 & $5.4290 E+03$ \\
\hline $237 u^{a}$ & 337.750 & $2.189 E-09$ & 5.00 & $8.3732 E+03$ \\
\hline \multirow{3}{*}{${ }^{239} \mathrm{Pu}$} & 340.450 & $4.059 E-10$ & 20.00 & $1.5523 E+03$ \\
\hline & 341.510 & $6.620 \mathrm{E}-07$ & 0.40 & $1.5187 E+03$ \\
\hline & 345.014 & $5.592 E-06$ & 0.20 & $1.2829 E+04$ \\
\hline
\end{tabular}

$a_{\text {Uranium-237 activity computed assuming }}{ }^{241} \mathrm{Pu}-{ }^{237} \mathrm{u}$ equilibrium. Uranium-237 branching ratio includes $2.46 \times 10^{-5241} \mathrm{Pu}$ alpha branch to $237 \mathrm{u}$.

\section{I. $\quad 640$-keV Region}

This is the only region above $160 \mathrm{keV}$ that we can use to measure ${ }^{240} \mathrm{Pu}$. To use this region for ${ }^{240} \mathrm{Pu}$, large samples are needed because of the low intensity of the $642.48-\mathrm{kev}{ }^{240} \mathrm{Pu}$ gamina ray. Nearby interferences from ${ }^{239} \mathrm{Pu}$ and especially ${ }^{24 \mathrm{l}} \mathrm{Am}$ at $641.42 \mathrm{keV}$ complicate the region. The 662.42-keV line of $24 \mathrm{l}_{\text {Am }}$ provides a good peak for americium measurements, as does the $645.97-\mathrm{keV}$ line for ${ }^{239} \mathrm{Pu}$. The other gamma rays in the ragion are not generally used but have to be taken into account for peak-fitting or responsefunction analysis.

A large-volume coaxial detector ( $10 \%$ relative efficiency or greater) should be used in this region; hence, analysis schemes that analyze data from this region as well as the $1100^{-}$to $400-\mathrm{keV}$ region may choose to use two detectors. 19 


\section{$332-\mathrm{keV}$ Region}

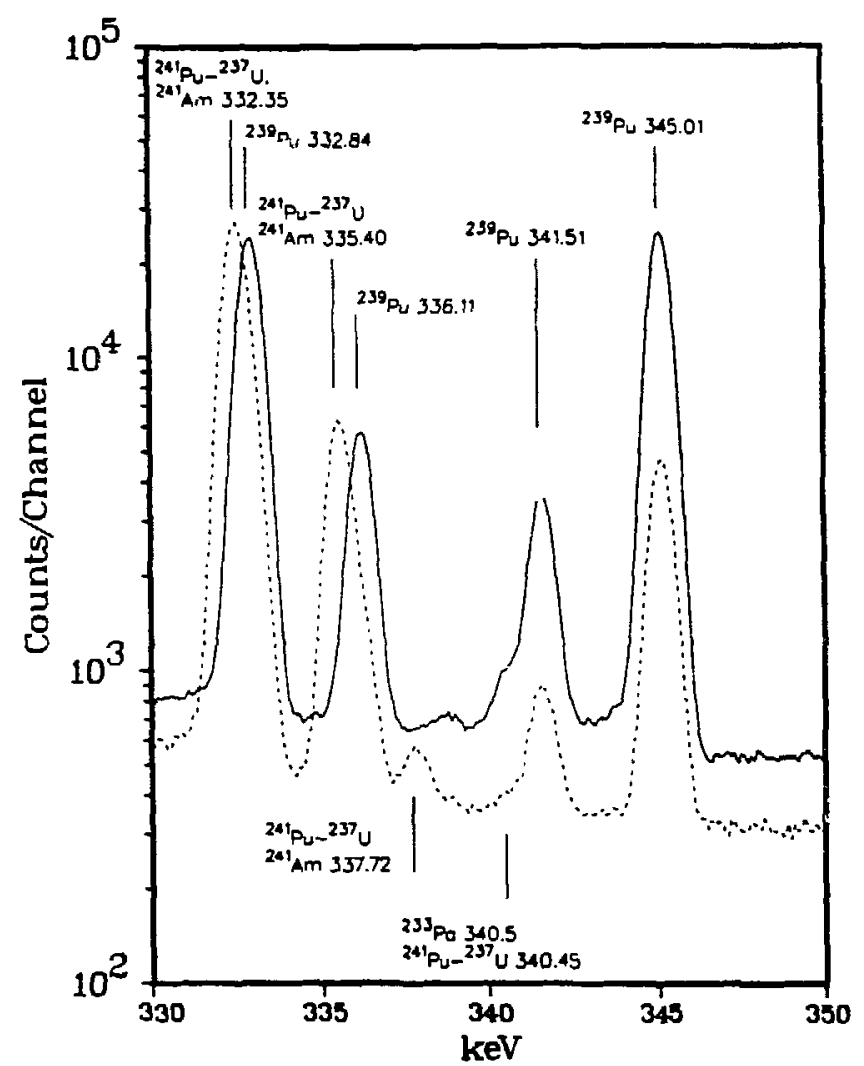

Fig. 11. Top (solid line)--PuO 2 counted with a $200-\mathrm{mm}^{2}$ by $10-\mathrm{mm}$-deep planar HpGe detector with resolution of $490 \mathrm{eV}$ at $122 \mathrm{keV}$. Isotopic composition (wtz): 238, 0.00248; 239, 97.968; 240, 2.01\%; 241, 0.020\%; 242, 0.0030\%; $241_{\mathrm{Am}}$, $11 \mu \mathrm{g} / \mathrm{g} \mathrm{Pu}$.

Bottom (dashed line)--same as top with isotopic composition (wtz): 238, 0.378\%; 239, 78.898; 240 , 15.288; 241, 4.428; 242, 1.048; $241_{\mathrm{Am}}$, $14300 \mu \mathrm{g} / \mathrm{g} \mathrm{Pu}$.

If common fission products, for example, ${ }^{95} \mathrm{zr}-{ }^{95} \mathrm{Nb}$ and ${ }^{137} \mathrm{Cs}$, are in the sample, the region may become useless for analysis. A level as low as $10 \mu \mathrm{Ci} / \mathrm{g} \mathrm{Pu}$ is sufficient to negate useful information from this region.

Figure 13 and Table XIII display this region. We have offset the data plots in Fig. 13 for clarity. 
COMPONENTS OF 332- AND 336-keV COMPLEXES (241 Am NEGLECTED)

\begin{tabular}{|c|c|c|c|}
\hline Isotope & 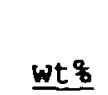 & $\begin{array}{c}\text { Percentage of } 332-k \epsilon ' \text { Complex } \\
\text { from Ind icated Isotope } \\
\end{array}$ & $\begin{array}{c}\text { Percentage of } 336-\mathrm{keV} \text { complex } \\
\text { Erom Indicated Isotope } \\
\end{array}$ \\
\hline 239 & 93.5 & 76.18 & 89.98 \\
\hline 241 & 0.3 & 23.98 & 10.18 \\
\hline 239 & 86.0 & 36.98 & 628 \\
\hline 241 & 1.5 & 63.18 & $38 \%$ \\
\hline 239 & 67.0 & 7.98 & $19.3 \%$ \\
\hline 241 & 8.0 & 92.18 & 80.78 \\
\hline
\end{tabular}

TV. MEASUREMENT PRINCIPLES

A. Isotopic Ratio/Measurement

In general terms we can write the photopeak counts of a specific gamma ray from a given isotope emitted from a sample of arbitrary configuration as

$$
C\left(E_{j}^{i}\right)=\lambda^{i} N^{i} \operatorname{BR}_{j}^{i} \in\left(E_{j}\right)
$$

where

$$
\begin{aligned}
& c\left(E_{j}^{i}\right)=\text { photopeak area of gamma ray } j \text { with energy } E_{j} \text { emitted } \\
& \text { from isotope } i \text {. } \\
& \lambda^{i}=\text { decay constant of isotope } i, \lambda^{i}=\ln 2 / T_{1 / 2}^{i} \\
& \text { (where } \mathrm{T}_{1 / 2}^{i} \text { is the half-life of isotope } i \text { ). } \\
& \mathrm{N}^{i}=\text { number of atoms of isotope } i \text {. } \\
& \mathrm{BR}_{\mathrm{J}}^{\mathrm{i}}=\text { branching ratio (gamma rays/disintegration) of gamma ray } \\
& j \text { from isotope } i \text {, and } \\
& \varepsilon\left(E_{j}\right)=\text { total efficiency for photopeak detection of gamma ray } \\
& \text { with energy } E_{j} \text {. This includes detector efficiency, } \\
& \text { geometry, sample self-absorption, and attenuation in } \\
& \text { materials between the sample and detector. }
\end{aligned}
$$




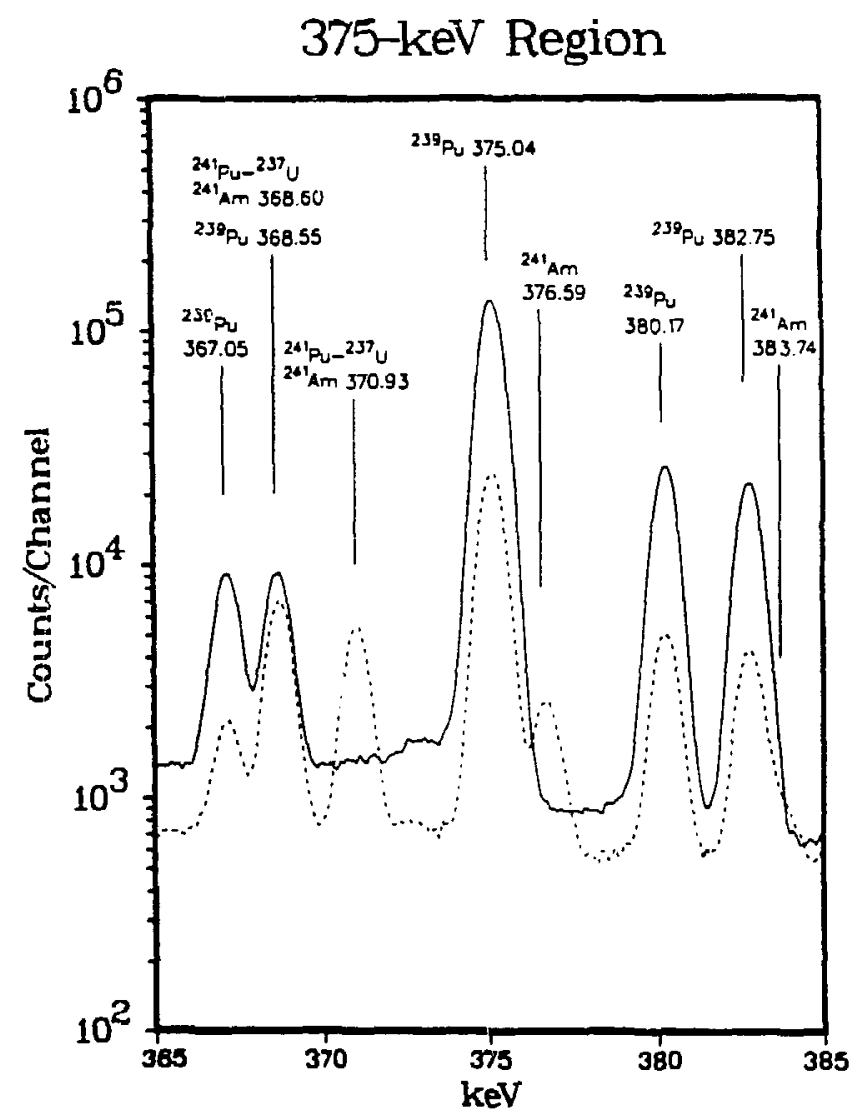

Fig. 12. Top (solid line)--PuO 2 counted with a $200-\mathrm{mm}^{2}$ by $10-\mathrm{mm}$-deep pianar HpGe detector with resolution of $490 \mathrm{eV}$ at $122 \mathrm{keV}$. Isotopic composition (wtz): 238, 0.0024\%; 239, 97.968; $240,2.01 \% ; 241,0.0208 ; 242,0.00308 ; 241 \mathrm{Am}$. $11 \mu \mathrm{g} / \mathrm{g} \mathrm{Pu}$.

Bottom (dashed lire)--same as top with isotopic composition (wtz): 238, $0.378 \%$; 239, 78.898; $240,15.28 \%$; 241, 4.428; $242,1.048 ; 241_{\mathrm{Am}}$, $14300 \mathrm{\mu g} / \mathrm{g} \mathrm{Pu}$.

In an analogous fashion we can write the count rate in terms of the mass of the isotope present as

$$
C\left(E_{j}^{i}\right)=M_{j}^{i} \gamma_{j}^{i} \varepsilon\left(E_{j}\right)
$$

where

$$
\begin{aligned}
M^{1}= & \text { mass of isotope } i(g) \text { and } \\
Y_{f}= & \text { photon emission rate of gamna ray } j \text { from isotope } i \\
& (\text { gammas } / s \cdot g \text { isotope). }
\end{aligned}
$$


TABLE XII

PEAK ENERGIES ANN INTENSITIES IN 375-keV REGION 8

\begin{tabular}{|c|c|c|c|c|}
\hline Isotope & $\begin{array}{r}\text { Energy } \\
(\mathrm{keV}) \\
\end{array}$ & $\begin{array}{l}\text { Branching Ratio } \\
\text { (photons/dis) } \\
\end{array}$ & $\begin{array}{l}\text { Error } \\
(\$) \\
\end{array}$ & $\begin{array}{c}\text { Activity } \\
\text { Shotons/s-g) }\end{array}$ \\
\hline${ }^{239} \mathrm{Pu}$ & 367.050 & $8.650 E-07$ & 0.30 & $1.9844 E+03$ \\
\hline & 368.550 & $9.030 E-07$ & 0.30 & $2.0716 E+03$ \\
\hline & 368.605 & $1.055 E-08$ & 2.00 & $4.0360 E+04$ \\
\hline & 368.605 & $2.170 E-06$ & 0.30 & $2.7462 E+05$ \\
\hline${ }^{237} \mathrm{u}^{3}$ & 370.934 & $2.713 E-08$ & 1.40 & $1.0377 E+05$ \\
\hline${ }^{24} \mathrm{l}_{\mathrm{Am}}$ & 370.934 & $5.230 E-07$ & 0.80 & $6.6186 E+04$ \\
\hline${ }^{239} \mathrm{Pu}$ & 375.042 & $1.570 E-05$ & 0.10 & $3.6018 E+04$ \\
\hline & 376.595 & $1.383 E-06$ & 0.70 & $1.7502 \mathrm{E}+05$ \\
\hline $\mathrm{Pu}$ & 380.166 & $3.051 E-06$ & 0.20 & $6.9995 E+03$ \\
\hline & 382.751 & $2.587 E-06$ & 0.20 & $5.9350 E+03$ \\
\hline${ }^{241} \mathrm{Pu}$ & 383.740 & $2.820 E-07$ & 1.50 & $3.5687 E+04$ \\
\hline
\end{tabular}

\footnotetext{
Eranium-237 activity computed assuming $241_{\mathrm{Pu}}{ }^{237} \mathrm{U}$ equilibrium. Uranium-237 branching ratio includes $2.46 \times 10^{-5} 241$ Pu alpha branch to $237 \mathrm{u}$.
}

We may rearrange these two equations to give expressions for the atom ratio of two isotopes from Eq. (1) and the mass ratio of two isotopes from Eq. (2).

The atom ratio of isotope $i$ to isotope $k$ from measurement of a gamma ray with energy $E_{j}$ from isotope $i$ and $E_{\ell}$ from isotope $k$ is given by

$$
\frac{N^{i}}{N^{k}}=\frac{C\left(E_{j}^{i}\right)}{C\left(E_{\ell}^{k}\right)} \times \frac{T_{1 / 2}^{i}}{T_{1 / 2}^{k}} \times \frac{B R_{l}^{k}}{B R_{j}^{i}} \times \frac{R E\left(E_{\ell}\right)}{R B\left(E_{j}\right)} .
$$

The similar expression for the mass ratio is

$$
\frac{M^{i}}{M^{k}}=\frac{Z\left(E_{j}^{i}\right)}{C\left(E_{\ell}^{k}\right)} \times \frac{Y_{\ell}^{k}}{Y_{j}^{i}} \times \frac{R E\left(E_{\ell}\right)}{R E\left(E_{j}\right)} .
$$




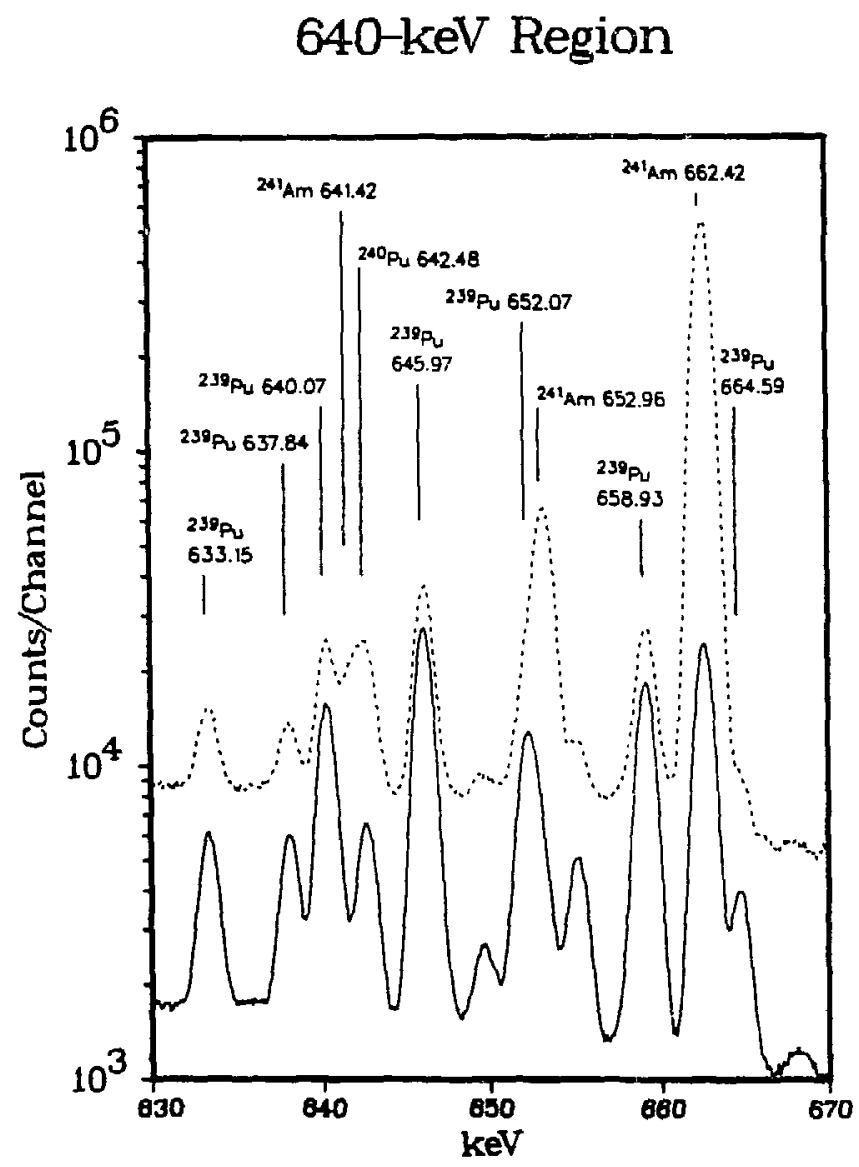

Fig. 13. Top (dashed line)- $-530 \mathrm{~g}$ plutonium as $\mathrm{PuO}_{2}$ counted with 10.28 relative efficiency coaxial HpGe detector with $1.65-\mathrm{keV}$ resolution at $1332 \mathrm{keV}$. Isotopic composition (wt\%): 238, $0.3028 ; 239,82.498 ; 240,13.758 ; 241,2.698$; $242,0.768 ; 241_{\mathrm{Am}}, 11800 \mathrm{\mu g} / \mathrm{g} \mathrm{Pu}$.

Bottom (solid line)- $-500 \mathrm{~g}$ plutonium metal. counted with 11.78 relative efficiency coaxial HpGe detector with $1.75-\mathrm{keV}$ resolution at 1332 $\mathrm{keV}$. Isotopic composition (wtz): 238, 0.0128; 239, 93.828; 240, 5.908; 241, 0.2408; 242, $0.028 \%$; $24 l_{\mathrm{Am}}, 630 \mathrm{\mu g} / \mathrm{g} \mathrm{Pu}$.

In Eqs. (3) and (4), the total efficiency has been rewritten in terms of the relative efficiency RE. Geometry factors cancel, and the ratio of efficiencies (relative efficiency) at energies $E_{\ell}$ and $E_{j}$ includes sample self-absorption, attenuation in materials between the sample and detector, and detector efficiency. The half-lives, $\mathrm{T}_{1 / 2}$; branching ratios, $\mathrm{BR}$; and photon 
TABLE XIII

PEAK ENERGIES AND INTENSITIES IN 640-keV REGION ${ }^{8}$

\begin{tabular}{|c|c|c|c|c|}
\hline Isotope & $\begin{array}{r}\text { Energy } \\
(\mathrm{keV})\end{array}$ & $\begin{array}{c}\text { Branching Ratio } \\
\text { (photons/dis) }\end{array}$ & $\begin{array}{c}\text { Error } \\
(z)\end{array}$ & $\begin{array}{c}\text { Activity } \\
(\text { photons } / s \cdot q)\end{array}$ \\
\hline \multirow{4}{*}{${ }^{241} \mathrm{Am}$} & 633.000 & $1.260 E-08$ & 15.00 & $1.5945 E+03$ \\
\hline & 633.150 & $2.530 E-08$ & 1.20 & $5.8042 E+01$ \\
\hline & 637.837 & $2.560 E-08$ & 1.20 & $5.8730 E+01$ \\
\hline & 640.075 & $8.200 E-08$ & 0.60 & $1.8812 E+02$ \\
\hline \multirow{6}{*}{$\begin{array}{l}{ }^{241} \mathrm{Am} \\
{ }^{240} \mathrm{Pu} \\
{ }^{239} \mathrm{Pu}\end{array}$} & 641.420 & $7.100 E-08$ & 4.00 & $8.9851 E+03$ \\
\hline & 642.480 & $1.245 E-07$ & 1.00 & $1.0454 E+03$ \\
\hline & 645.969 & $1.489 E-07$ & 0.40 & $3.4160 \mathrm{E}+02$ \\
\hline & 649.321 & $7.120 E-09$ & 7.00 & $1.6334 E+01$ \\
\hline & 650.529 & $2.700 E-09$ & 15.00 & $6.1942 E+00$ \\
\hline & 652.074 & $6.550 E-08$ & 0.60 & $1.5027 E+02$ \\
\hline \multirow{3}{*}{$\begin{array}{l}241_{\mathrm{Am}} \\
239^{\mathrm{Pu}}\end{array}$} & 652.960 & $3.770 E-07$ & 2.00 & $4.7710 E+04$ \\
\hline & 654.880 & $2.250 E-08$ & 1.20 & $5.1618 E+01$ \\
\hline & 658.929 & $9.690 E-08$ & 0.70 & $2.2230 E+02$ \\
\hline \multirow{3}{*}{$\begin{array}{l}{ }^{241} \mathrm{Am} \\
{ }^{239} \mathrm{Pu}\end{array}$} & 662.420 & $3.640 E-06$ & 0.30 & $4.6065 E+05$ \\
\hline & 664.587 & $1.657 E-08$ & 1.60 & $3.8014 E+01$ \\
\hline & 668.200 & $3.930 E-10$ & 30.00 & $9.0160 E-01$ \\
\hline
\end{tabular}

emission rates are either known nuclear data or can be calculated from known nuclear data.

The $C(E)$ are measured, leaving only the ratio of efficiencies to be determined. The need for nothing more than an efficiency ratio removes the problems associated with the geometrical reproducibility associated with absolute measurements and makes the method applicable to samples of arbitrary size, shape, and composition.

For every sample, we can determine the ratio of the relative efficiency at selected energies from the measured spectrum of that sample. Looking at Eq. (1) and considering a series of gamma-ray lines from a single isotope, we 
see that the quotient of the photopeak counts at energy $E_{j}^{1}$ and the branching ratio $\mathrm{BR}_{j}^{1}$ is proportional to the efficiency at energy $E_{j}$.

$$
\frac{C\left(E_{j}^{1}\right)}{B R_{j}^{1}} \propto \varepsilon\left(E_{j}\right)
$$

Thus, this quotient can define the shape of the relative efficiency for that sample measurement. In an analogous fashion, we could use Eq. (2) to define the relative efficiency by replacing $B R_{j}^{i}$ in Eq. (5) with $r_{j}^{i}$. Because ratios are used, all that is important is the shape of the curve.

With a series of points from a single isotope defining the shape of the relative efficiency curve, we can apply curve-fitting techniques ${ }^{16}$ to define the relative efficiency at an arbitrary energy or simply interpolate between measured points. To better define the shape of these relative efficiency curves, we can use points from more than one isotope by normalizing one isotope to another. ${ }^{16,17}$ Gamma rays from ${ }^{239} \mathrm{Pu}$ and ${ }^{241} \mathrm{Pu}-{ }^{237} \mathrm{v}$ are most often used to define the relative efficiency curves in the range from 130 to $450 \mathrm{keV}$.

Measuring isotopic ratios for closely spaced gamma rays from different isotopes is advantageous because relative efficiency ratios will be near unity. However, even for closely spaced lines in the 120- to 200-keV region, we cannot neglect this correction. A typical correction for the 152.7-kev ${ }^{238} \mathrm{Pu} /$ 148.6-kev ${ }^{241} \mathrm{Pu}$ ratio can be $10 \%$.

After appropriate isotopic ratios are measured, it is uslially desirable to combine them to produce isotopic fractions. First, we must convert all measured ratios to a common denominator, say ${ }^{241} \mathrm{Pu}$ for the purpose of illustration. Then, neglecting ${ }^{242} \mathrm{Pu}$, we observe

$$
1=\mathrm{E}_{238}+\mathrm{E}_{239}+\mathrm{E}_{240}+\mathrm{E}_{241}
$$

where $E_{i}$ is the isotopic fraction of isotope 1 . 
Dividing by $E_{241}$ we get

$$
\frac{1}{E_{241}}=\frac{E_{238}}{E_{241}}+\frac{E_{239}}{E_{241}}+\frac{E_{240}}{E_{241}}+1 .
$$

giving an expression for the isotopic fraction of ${ }^{24 l_{\mathrm{Pu}}}\left(\mathrm{f}_{241}\right)$ in terms of the three measured ratios $\mathrm{E}_{238} / \mathrm{E}_{241}, \mathrm{E}_{239} / \mathrm{E}_{241}$, and $\mathrm{E}_{240} / \mathrm{E}_{241}$. We obtain the remainder of the isotopic fractions from

$$
\mathrm{f}_{i}=\mathrm{E}_{241} \times\left[\frac{\mathrm{E}_{1}}{\mathrm{f}_{241}}\right] \text {. }
$$

where $i=238,239$, and 240 .

Section V.C discusses the incorporation of ${ }^{242} \mathrm{Pu}$ into this analysis. If the ratio of ${ }^{241} \mathrm{Am}$ to any of the plutonium isotopes (usually ${ }^{239} \mathrm{Pu}$ ) has been measured, we find the absolute fraction of ${ }^{241}$ Am by

$$
E_{A m}=E_{i} \times \frac{E_{A m}}{E_{i}} .
$$

Note that this gives the weight or atom fraction of ${ }^{241}$ Am in the sample with respect to total plutonium, not total sample.

For this method to work, the plutonium in the sample must be isotopically homogeneous even though it may be physically and geometrically inhomogeneous. This restriction also applies to the ${ }^{241} \mathrm{Am}$ in the sample. The Am/Pu ratio must be uniform throughout all of the plutonium in the sample.

\section{B. Absolute Isotopic Mass Measurement}

While the ratio method discussed in Sec. IV.A can be applied to arbitrary samples, a more specialized method has also been used in the case of samples with reproducible geometries. Gunnink and coworkers $4,11,15$ have used the 
method of absolute measurement of the amount of each isotope in the solution samples. This me:hod depends upon the equation

$$
c\left(E_{j}^{i}\right)=k_{j}^{i} m^{i}
$$

with

$$
\begin{aligned}
C\left(E_{j}^{i}\right)= & \text { photopeak area of gamma ray } j \text { with energy } E_{j} \\
& \text { emilted from isotope } i, \\
m^{i}= & \text { mass of isotope } i \text { in sample, and } \\
k_{j}^{i}= & \text { calibration constant for gamma ray } j \text { from isotope } 1 .
\end{aligned}
$$

This technique uses direct calibration with standard samples identical in geometry to the unknowns to determine the calibration constants. Self-attenuation corrections may be needed to account for differences between calibration standards and unknowns. Given the amount of each isotope in the sample, we obtain the isotopic Eractions from

$$
\mathrm{f}_{i}=\frac{\mathrm{m}_{\mathrm{i}}}{\sum_{1-238}^{241} \mathrm{~m}_{i}}
$$

For these measurements, the size and shape of the samples are carefully chosen to ininimize (but not eliminate) self-absorption corrections. This is an example of the sample being made to fit the method rather than vice versa. We next discuss application of ${ }^{242} \mathrm{Pu}$ correlation techniques to this procedure and ratio methods.

\section{C. ${ }^{242} \mathrm{Pu}$ Isotopic Correlation}

Section II.C mentioned that ${ }^{242} \mathrm{Pu}$ cannot be measured directly because of its low activity. low abundance, and weak gamma rays. Instead, given knowledge of the other isotopic fractions in the sample, we use isotopic correlation $^{7}$ techniques to predict the ${ }^{242} \mathrm{Pu}$ abundance. It is well known that correlations exist among the plutonium isotopic abundances. These correlations 
arise from the 1sotope production process. These correlations depend upon the reactor type and details of the plutonium's irradiation history, so it is difficult, if not impossible, to find a single correlation that is optimum for all material. Gunnink ${ }^{7}$ suggests a correlation of

$$
242=\frac{K(240)(241)}{(239)^{2}}
$$

as being linear and relatively independent of reactor type. In Eqs. (12) and (13), the isotope mass number represents the isotopic fraction of that isotope. This correlation applies at reactor discharge time. Gunnink finds a best-fit constant $K$ to have a value of 52 when the isotopes are given in weight percent. one disadvantage to this correlation is its dependence on ${ }^{241} \mathrm{Pu}$, which decreases in absolute abundance by about $5 \%$ per year. To make best use of this correlation we must correct the ${ }^{241} \mathrm{Pu}$ abundance to reactor discharge time. Often this time is not known, but we can make a partial correction, back to the last chemical separation, by adding the ${ }^{241} \mathrm{Am}$ ingrowth back to the ${ }^{241} \mathrm{Pu}$ content before computing the correlation.

A correlation not involving ${ }^{241} \mathrm{Pu}$ has been suggested; 7,20

$$
242=\frac{K(240)^{3}}{(239)^{2}} .
$$

This correlation is linear for a given reactor type, but the slope $K$ depends upon the specific reactor.

Once the isotopic fraction of ${ }^{242}$ Pu has been found using a suitable correlation, known values, or stream averages, the other measured isotopic fractions are correctec iy

$$
E_{i}^{c}=E_{i}\left(1-E_{242}\right)
$$

where

$$
\begin{aligned}
& E_{i}^{C}=\text { normalized isotopic Eractions including }{ }^{242} \mathrm{Pu} \text { and } \\
& E_{i}=\text { normalized isotopic fractions without }{ }^{242} \mathrm{Pu} .
\end{aligned}
$$


This preserves the normalization condition that the isotopic fractions sum to unity.

\section{DATP. ACQUISITION}

\section{A. Electronics}

Plutonium isotopic measurements use conventional, high-quality, nuclear instrumentation module (NIM) type electronics. Several manufacturers provide excellent modules. Methods using fixed ROI or response-function methods for obtaining peak areas require digital gain and zero stabilization . A bias supply suitable for a high-resolution germanium detector and an amplifier with baseline restoration, pileup rejection, and time constants in the 1- to 6- $\mu \mathrm{s}$ range are required. Other modules often used are liquid-nitrogen-level monitors, scalers or rate meters to monitor detector count rates, and oscilloscopes to aid in setup and troubleshooting.

Most methods require a multichannel analyzer (MCA) with a 4-k channel memory. Two-detector systems require two analog-to-digital converters and 8-k memory to divide between the two detectors.

The extensive data analysis requirements dictate that the MCA interface with a computer. Sixteen-bit minicomputers with a $32-k$ word memory are adequate. $A$ disk is needed for program and data file storage. Simple analysis can be done with programmable calculators once peak areas are obtained.

\section{B. Detectors}

All data analysis methods benefit from the the best possible resolution and peak shape. These criteria are the most important parameters when considering a detector for a plutonium isotopic system. The most common detectors are planar HpGe detectors with a common size being $200 \mathrm{~mm}^{2}$ by $10-13 \mathrm{~mm}$ deep, which gives a good tradeoff between resolution and efficiency. Resolutions of $<500 \mathrm{eV}$ at $122 \mathrm{keV}$ are commercially available with this size detector. A peak shape specification of 2.55 or better for the ratio of full width at one-fiftieth maximum to full width at half maximum (FWHM) at $122 \mathrm{keV}$ will help ensure good peak shape. Good detectors give values of below 2.5 for this parameter with no background subtraction. Planar detectors can be used up to $400 \mathrm{keV}$. High-quality coaxiai detectors can be used in the 100- to 400-keV region, but they do worsen the problem of partially resolved peaks for methods using ROI surmation techniques. 
For measurements in the 600-keV region, a coaxial detector is better because the planar efficiency is roo low. Ten percent relative efficiency is adequate, and bigger detectors can profitably be used. Again, resolution is important. The very best resolution may negate the need tc peak fit the entire 600-kev region. ${ }^{16}$ Resolutions of $1.7 \mathrm{keV}$ or better at $1332 \mathrm{keV}$ are available. Detector geometry may be either uplooking or sidelooking. The physical constraints of the measurement area often dictate the geometry.

\section{Filters}

Filtering is required to reduce the count rate from the $59.54-\mathrm{keV}{ }^{241} \mathrm{Am}$ line that dominates any unfiltered spectrum from an aged sample. If left unfiltered, the americium peak will cause unnecessary deadtime and will sum with $x$ rays and gamma rays in the $100-\mathrm{keV}$ region to produce interferences in the 150 - to $165-\mathrm{keV}$ region. A thickness of $0.060 \mathrm{in.}(0.15 \mathrm{~cm})$ of either lead or cadmium will attenuate a $60-\mathrm{keV}$ gamma ray by a factor of over 1000. A graded filter will suppress $x$ rays from the main filter, with $0.010 \mathrm{in}$. $(0.025 \mathrm{~cm})$ of copper suppressing cadmium $\mathrm{K} x$ rays at $22 \mathrm{keV}$ by a factor of 100 . Lead $\mathrm{x}$ rays (72-87 kev) from shielding often appear in the spectrum. As much as $0.090 \mathrm{in}$. $(0.23 \mathrm{~cm})$ of cadmium is needed to suppress these.

A reasonable rule of thumb is to filter enough to reduce the peak height at $60 \mathrm{keV}$ to less than those in the 100-kev region. Too much filtering will unnecessarily reduce the intensity of the peaks in the 120 - to 200-keV range (see Sec. III.C). Trial-and-error experiments with high-americium content samples are usually necessary to see if filtering is sufficient. The region between 153 and $160 \mathrm{keV}$ should be flat. 19

Little, if any, filtering is needed for freshly separated samples (no $241_{\mathrm{Am}}$ or $237 \mathrm{u}$ ) when using the $100-\mathrm{keV}$ region or the $40-\mathrm{keV}$ region.

\section{Sample Considerations}

Methods designed for arbitrary sample configurations do not have geometry or positioning requirements. One uses distance or collimation to tailor the count rate. Count rates are kept reasonably low to maximize resolution and usually fall in the 5- to $15-\mathrm{kHz}$ range. Developments in high-count-rate spectroscopy 21,22 hold the promise of increasing this range significantly.

There is a current trend to higher counting rates and shorter shaping times to obtain more throughput for methods relying on the analysis of gamma 
rays above $120 \mathrm{keV}$. These higher-count-rate methods still use conventional electronics operating with shorter time constants $(\sim 1 \mu s)$ that reduce deadtime and pileup losses. Rates up to $50 \mathrm{kHz}$ are reasonable with throughput increases by approximately a factor of 3 over a $3-\mu \mathrm{s}, 15-\mathrm{kHz}$ measurement. These higher counting rates do worsen the system resolution. One must be certain that the chosen analysis method is robust enough to handle the poorer resolution.

Measurements on solutions usually use a Eixed-sample geometry with a disposable sample vial or a fixed, refillable sample cell. The cell thickness is usually tailored to the sample concentration range and the energy range to minimize the attenuation corrections needed for absolute counting methods.

Coincidence summing effects may be present if small samples are placed close to the detector. 18 Experimenters have noted an effect of $1.6 \%$ for 3to 4-cm sample distance with the use of a planar detector for the $129+203 \mathrm{keV}$ $=332-\mathrm{keV}$ lines from ${ }^{239} \mathrm{Pu}$. Bulk samples will generally be farther away, making this effect less important.

The analysis schemes described previously requitre that the plutonium be isotopically homogeneous and that the americium/plutonium ratio be uniform if americium measurements are desired. If the homogeneity requirements are satisfied, the sample need not be rotated. If the homogeneity requirements are not satisfied, rotation will still. not ensure a correct answer, but it can reduce errors in most cases.

Common electrochemical processes produce residues such as slag, crucibles, and salts in which there may be a physical segregation of the plutonium and americium. For samples where the correct americium content is needed for calorimetry measurements, the arbitrary sample methods described previously will not be accurate. Current research ${ }^{23}$ has led to an analysis method that corrects for inhomogeneous americium/plutonium content by using a separate relative efficiency curve for americium peaks. One should validate this method For the specific sample types to be measured because results can be dependent on the sample size anis composition.

Bulk samples (containing kilogram quantities of plutonium) have high neutron emission rates $\left(10^{5}\right.$ to $\left.10^{6} \mathrm{n} / \mathrm{s}\right)$. Long exposure to large samples can cause neutron damage to the detector. Detector performance nay significantly deteriorate in one year of heavy usage. With this in mind, controlling the count rate by increasing the sample-to-detector distance or by opening up the 
collimation becomes desirable as opposed to tightening collimation or decreasing the sample distance. One wishes to use the greatest sample-to-detector distance consistent with count-rate requirements to decrease the neutron flux at the detector. In addition, neutron interactions in the detector increase the continuum under the photopealis, which worsens the measurement precision.

\section{E. Counting Time}

The counting time required to produce accountability-quality isotopic precision is a function of the spectral region studied. In the 40- and 100-kev regions, counting times of $1000 \mathrm{~s}$ to $1 \mathrm{~h}$ are usually satisfactory. For bulk samples of arbitrary geometry using gamma rays above $120 \mathrm{keV}$, counting times of $l$ or $2 \mathrm{~h}$ or longer are necessary and still do not produce as good a precision as shorter times in the lower-energy regions. For larger samples, simple verification of the ${ }^{239} \mathrm{Pu} /{ }^{241} \mathrm{Pu}$ ratio may take only a few minutes. Some specific examples will be discussed in Sec. VII.

\section{DATA ANALYSIS}

The general term data analysis can refer both to the method used to extract the photopeak areas and to the method used to combine the photopeak areas to obtain the required isotopic information. Below we will describe several of the methods and techniques used in systems that have been implemented in the United states. We do not wish to ignore methods used elsewhere but instead are attempting to concentrate on describing methods with which we are most familiar.

\section{A. ROI Summation}

This is the simplest method for extracting peak areas. ${ }^{24}$ Most MCAs feature a built-in form of this analysis. The background under the peak is determined using the average count in background regions defined above and beluw the peak of interest. Several methods are of ten used. The average backgrouni from the two RoIs (zero-slope line) can be ust. A sloping linear background between the centroids of the ROIs is another option. It gives the same results as the zero-slope average if the background ROIs are symmetric about the peak ROI. A smoothed step-function ${ }^{25}$ background, also common, probably provides the most physically realistic estimate for cases where the background does not have a positive slope. 
The smoothed step function has the form

$$
B_{i}=b_{n}+\left(b_{m}-b_{n}\right) \sum_{j=n}^{j=i} Y_{j} \sum_{k=n}^{k=m} Y_{k} \text {, }
$$

where

$B_{i}=$ computed background in channel $i$,

$Y_{i}=$ gross spectrum count in channel $i$,

$\mathrm{b}_{\mathrm{n}}$ = average background count in low-energy background ROI, and

$b_{m}=$ average background count in high-energy background ROI.

One should also subtract the high-energy background $b_{m}$ from the gross spectrum $Y$ before computing Eq. (15).

Needless to say, the ROI summation method works best for single isolated peaks. Indeed, there is little or no reason to do anything else to get the peak area of a single isolated peak. Overlapping peaks, for example, 125-, 160-, 332-, and 375-keV regions, are a different story. ROI summation can be used to get the area of multiplets, but one must isolate the individual components by an integral stripping method using neighboring peaks and known relative efficiency differences. This analysis generally leads to a loss of precision.

stabilizers are required to keep peaks within their fixed RoIs, and background windows must be chosen carefully to avoid contaminate peaks, for example, weak ${ }^{241} \mathrm{Am}$ peaks Erom high-americium-concentration samples.

The main advantage of ROI summation is that it is easy to implement, understand, and use.

\section{B. Peak Fitting}

Peak-fitting techniques have been in use in gamma-ray spectroscopy for decades. Techniques ${ }^{26}$ developed by Gunnink and coworkers at Livermore are widely used both for plutonium isotopic measurements and in other gamma-ray spectroscopy areas. The GRPANL 27 code has been automated at the Mound Facility ${ }^{28}$ and forms the basis for the GRPAUT ${ }^{16}$ program used there. 
This code flts a background-subtracted photopeak with a Gaussian function plus exponential tailing functions as

$$
Y_{i}=Y_{0}\left\{\exp \left[\alpha\left(X_{i}-X_{0}\right)^{2}\right]+T\left(X_{i}\right)\right\}
$$

with

$$
\begin{aligned}
Y_{i}= & \text { net counts in channel } x_{i} \text { for a single peak, } \\
Y_{0}= & \text { peak height at centroid }\left(x_{i}=x_{0}\right) . \\
\alpha= & -4 \ln 2 /(\text { FWHM })^{2}=-1 / 2 \sigma^{2} \text { with } \sigma \text { being the } \\
& \text { standard deviation of the Gaussian. } \\
X_{0}= & \text { peak centroid, and } \\
T\left(x_{i}\right)= & \text { tailing function at channel } x_{i} .
\end{aligned}
$$

The tailing function is given by

$$
\begin{aligned}
T\left(x_{i}\right)= & \left\{A \exp \left[B\left(x_{i}-x_{0}\right)\right]+C \exp \left[D\left(x_{i}-x_{0}\right)\right]\right\} \\
& \left\{1-\exp \left[0.4 \alpha\left(x_{i}-x_{0}\right)^{2}\right]\right\} \delta,
\end{aligned}
$$

where

$A$ and $C=$ short- and long-term tailing amplitude.

$B$ and $D=$ short- and long-term tailing slope, and

$$
\delta=1 \text { for } x_{i}<x_{0} ; \delta=0 \text { for } x_{i} \geq x_{0} \text {. }
$$

The right-hand bracket brings the tailing function smoothly to zero at the peak centroid shown in Fig. 14. For many applications we can neglect the long-term tail $(C=0)$; however, for large multiplets with strong peaks, including it is cesirable.

Each peak can have as many as seven parameters, $Y_{0}, X_{0}, \alpha, A, B, C$, and $D$, with the peak position $X_{0}$ and peak height $Y_{0}$ generally being the principal parameters of interest. Fortunately, we can predetermine many of the other parameters.

The FWHM (related to $\alpha$ ) can be determined as a function of gamma-ray energy $E^{\prime}$ as 


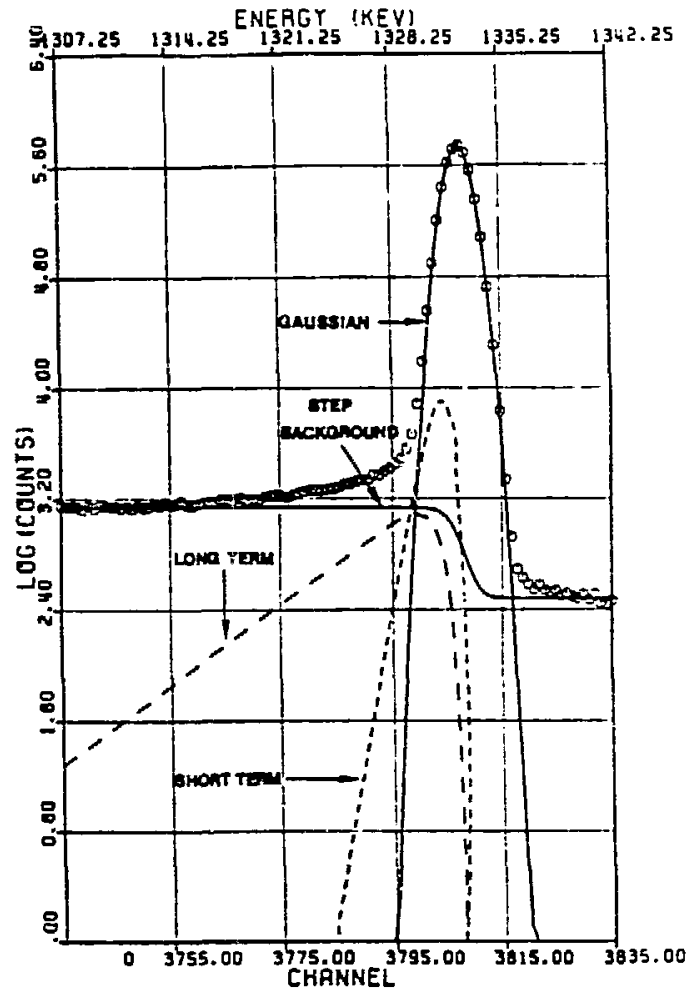

Fig. 14. Gamma-ray photopeak obtained with Ge(Li) detector showing (1) Gaussian, (2) short-term tailing. (3) long-term tailing, and (4) diffusedstep background contributions to spectral peak shape. 28

$$
\mathrm{FWHM}^{2}=\mathrm{k}_{2}+\mathrm{k}_{2} \mathrm{E} \text {. }
$$

The measured widths of two peaks in the spectruin can be used to find $k_{1}$ and $k_{2}$, thus giving the FWHM value at any energy.

Experience $^{26}$ shows that the short-term tailing slope $B$ is a constant for a given detector systēm. Measuring this for a high-energy peak where lailing is largest is desirable.

The short-term tailing amplitude $A$ is given by

$$
\ln A-k_{3}+k_{4} E \text {. }
$$

Once the short-term slope $B$ has been found, it is fixed, and then the shorl-term tail amplitude can be found from two peaks.

The GRPANL formalism also allows for the fitting of resolution-broadened $x$-ray peaks that have different intrinsic line shapes (Lorentzian) than do gamma rays. 29 only by using this feature can we do accurate peak fitting in the 100-keV region.

Before the fitting, the step-function background algorithm of Eq. (15) is used to remove the background. Then an iterative, nonlinear least-squares technique 26,27 is used to fit the peak.

Various "tricks" can reduce the number of Eree parameters in the fitting process. For plutonium isotopics, the peak energies are known; 8 thus, positions of peaks in a multiplet may be fixed relative to one peak in the group. Because relative peak intensities Erom the same isotope are also known, these may be fixed, too. 
Because the method is an iterative technique, data analysis times can be fairly long. The time depends upon the number of peaks and number of free parameters, as well as upon the type of computer and disk. A typical time for analysis of a plutonium spectrum from 120 to $450 \mathrm{keV}$ with over 50 peaks in aboul 15 groups may be about $10 \mathrm{~min}$ on a PDP-11/23. This time is usually not significant when we consider that data accumulation times can be a factor of 10 longer.

\section{Response-Function Analysis}

This method uses the peak-fitting principles discussed above to calculate the shape of the detector response to a particular isotope in a particular energy region. With the shape of the response known, only the peak height or envelope height $\left[Y_{0}\right.$ in Eq. (16)] is unknown. The fitting probleil is then reduced to a linear least-squares problem, which is quickly solved.

To carry out this type of analysis, the peak-shape characteristics of the detector must be predetermined or acquired from the spectrum of the sample under study. If the short-term tail slope $B$ has been predetermined for the detector, then fitting two photcpeaks (one low energy and one high energy) can give the variation of the FWHM with energy [Eq. (18)] and the variation of the short-term tail amplitude [A, Eq. (19)] with energy. We usually do this as part of premeasurement calibration and store these parameters in a data file to be used later. Long-term tail parameters, if used, are also determined at this time.

Differences in count rates between samples can affect the FWHM of the peaks. This can be accounted for by determining the FWHM of a low-energy peak in each spectrum, $60-\mathrm{keV}{ }^{241} \mathrm{Am}$, for example, and adjusting the noise term, $\mathrm{K}_{1}$ in $\mathrm{Eq}$. (18), for the FWHM in $\mathrm{E}$.

This procedure enables us to know all the shape parameters, energies, and peak positions for spectral lines in each spectrum. We can then compute the response profile for each isotope in the region to be fitted. For the 100-keV region that contains $x$ rays, we use the formalism of Ref. 29 to compute the $x$-ray line shapes. Only linear equations are left to solve for the relative intensities of each isotope contributing to the region. Some counting situations can yield absolule intensities for the fitled data if previous calibrations exist. 
This method has been used to $\mathrm{fit}$ the complex 100-kev region ${ }^{4,11,15}$ and also for spectra in the 120 - to $370-k$ ev region. 30

\section{IMPLEMENTED SYSTEMS}

In this section we will describe some systems that have been put into routine use in the United states and their characteristics, accuracies, and precisions.

\section{A. Rockwel1-Hanford}

The system in use at Rockwel1-Hanford ${ }^{31}$ probably ras been used more than any other system for measuring solids. It uses four $300-\mathrm{mm}^{2}$ by 7 -mm-deep planar HpGe detectors to measure oxides, metals, impure oxides, mixed oxides, and scrap. Figure 15 shows a photograph of two of the detectors. Data are taken from the MCA to an offf-line computer for analysis. Ratio methods are used on peaks in the $120-$ to $400-\mathrm{keV}$ range using the methods outlined in Ref. 3. Software is being updated based on more recent work. ${ }^{16}$

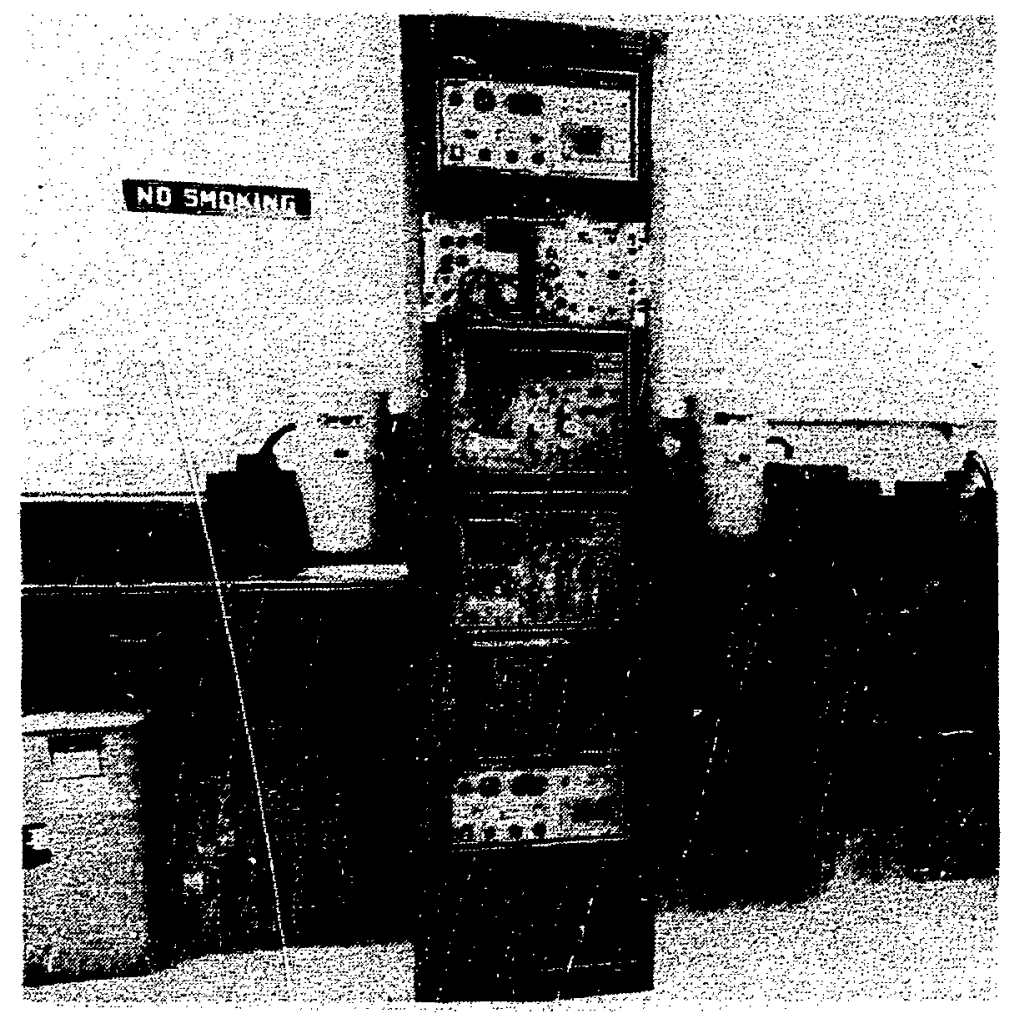

Fig. 15. Plutonium isotopic system implemented at Rockwell-Hanford. (Photo courtesy of R. A. Hamilton, Rockwel l-Hanford.) 
Samples are counted for $10000 \mathrm{~s}$ at a count rate of $3000 \mathrm{~Hz}$ with the sample-to-detector distance adjusted to give the desired count rate. No sample rotation is used.

A large volume of performance data exists for this instrument on 14 standards spanning the range from $2 \%$ to $24 \% 240 \mathrm{Pu}$. The isotopic ratio expressions use only the fundamental branching ratios and half-lives. No bias corrections are made. Plutonium-242 is not calculated. Table XIV shows some of the performance data as they apply to the speciflc power used to interpret calorimetry.

Measurement precision for the specific power is in the $0.5 \%$ to $1.0 \%$ RSD range, with measurement bias being of the same order.

Plutonium isotopic measurement by gamma-ray spectroscopy is somewhat forgiving when used to compute the specific power. Biases in one isotopic fraction are partially cancelled by the normalization condition that all isotopes must sum to unity.

\section{B. Los Alamos}

The Plutonium Processing Eacility at Los flamos uses the basic methods of Ref. 3 as described in Refs. 17 and 32. Gain-stabilized data in the 120- to 400-kev region are acquired with 200-ma ${ }^{2}$ by 13-mm-deep planar HpGe detectors at rates up to $20 \mathrm{kHz}$ with time constants of 2 or $3 \mu \mathrm{s}$. Analysis is done online and has been applied to material with $2 \%$ to $18 \%{ }^{240} \mathrm{Pu}$ and with ${ }^{241} \mathrm{Am}$ up to $2.0 \%$. All ratios are measured with respect to ${ }^{241} \mathrm{Pu}$, and Table XV tabulates the different ratios used for aged and freshly separated material. Peak areas are determineà using simple ROI summation.

A correlation of the form of Eq. (12) $\left(242=k \times 240 \times 241 / 239^{2}\right)$ is used to compute ${ }^{242} \mathrm{Pu}$. A constant with the value of 90 is used to give a result in weight percent for material with a wide variety of reactor histories.

Because ROI integration is used for peak areas, interfering peak areas must be subtracted using clean neighboring peaks. The 129.3-keV peak is used to subtract ${ }^{239} \mathrm{Pu}$ interferences from the $125-\mathrm{keV}$ region. The $164.6-\mathrm{keV}$ peak is used to subtract ${ }^{241} \mathrm{pu}$ from the $160-\mathrm{keV}$ complex for aged samples. The $161.5-\mathrm{keV}{ }^{239} \mathrm{Pu}$ peak is used to subtract the small ${ }^{239} \mathrm{Pu}$ interference Erom the $160-\mathrm{keV}$ complex. At the $332-\mathrm{keV}$ region, the $345-\mathrm{kev}{ }^{239} \mathrm{Pu}$ peak is used to remove interferences at 332.8 and $336.1 \mathrm{keV}$. The ${ }^{241} \mathrm{Pu}-{ }^{237} \mathrm{U},{ }^{241}$ Am lines at 332.4 and $335.4 \mathrm{keV}$ are used to compute the ${ }^{241} \mathrm{Pu} /{ }^{241}$ An ratio, ${ }^{3}$ which is in 
TABLE XIV

PERFORMANCE OF ROCKUELL-HANFORD ISOTOPICS SYSTEM FOR SPECIPIC POWER

Isotope

$\mathrm{s}^{238} \mathrm{Pu}$

$8{ }^{239} \mathrm{Pu}$

$8240 \mathrm{Pu}$

$q^{241} \mathrm{Pu}$

$8^{241}$ Am

No. of measurements

Precision of specific

power ( 8 RSD) calculated

from measurement reproduci-

bility

Blas: Specific power from

NDA divided by specteic

power from mass spectrometry

values 1(oxide) 2(metal) 3(oxide) 4(oxide) 5(oxide) 6(metal) 7(metal)

$\begin{array}{lcccccc}0.0063 & 0.0008 & 0.028 & 0.14 & 0.064 & 0.069 & 0.089 \\ 97.56 & 93.73 & 91.64 & 87.87 & 86.50 & 80.77 & 73.81 \\ 2.40 & 6.03 & 7.65 & 10.23 & 11.78 & 17.10 & 22.83 \\ 0.038 & 0.21 & 0.569 & 1.49 & 1.42 & 1.66 & 2.26 \\ 0.059 & 0.138 & 0.447 & 1.26 & 0.088 & 1.12 & 2.13\end{array}$

102

103

102

109

98

103

101

$\begin{array}{lllllll}1.028 & 0.728 & 0.658 & 0.558 & 0.848 & 0.628 & 0.538\end{array}$

0.9914

0.9921

1.003

1.008

1.016

1.002

1.028

TABLE XV

RATIOS USED IN LOS ALAMOS PLUTONIUM ISOTOPIC SYSTEM

Ratio

Aged

Freshly Separated

$238 / 241$

$152.7 / 148.6 \mathrm{keV}$

$152.7 / 148.6 \mathrm{keV}$

$239 / 241$

$345.0 / 332.4 \mathrm{keV}$

$203.5 / 208.0 \mathrm{keV}$

wtg Av

$129.3 / 148.6 \mathrm{keV}$

$240 / 241$

$160.3 / 164.6 \mathrm{keV}$

$160.3 / 148.6 \mathrm{keV}$

$\mathrm{Am} / 239$

$125.3 / 129.3 \mathrm{keV}$

wtg Av

$125.3 / 129.3 \mathrm{kev}^{\mathrm{a}}$

\footnotetext{
americium content is usually too low to measure.
} 
turn used to correct ${ }^{241} \mathrm{Pu}^{237} \mathrm{U}$ peaks at $164.6,208.0,267.5$, and $332.4 \mathrm{keV}$ for their $241_{\text {Am content. }}$.

Relative efficiency is found Erom ${ }^{239} \mathrm{Pu}$ and ${ }^{241} \mathrm{Pu}-{ }^{237} \mathrm{U}$ lines normalized to each other. Simple linear and quadratic interpolation and extrapolation provide needed values. Figure 16 shows typical curves.

The simple RoI integration method can present problems in obtaining biasfree peak areas where there are close interferences, for example, $125 \mathrm{keV}$, $160 \mathrm{keV}$, and $332 \mathrm{keV}$. For this reason, each isotopic ratio is calibrated with standard samples allowing one calibration constant for each term in the isotopic ratio expression. Figure 17 shows the average accuracy of the system after such a calibration with a wide variety of samples, metal and oxide from $<10.5 \mathrm{~g} \mathrm{Pu}$ to $\sim \mathrm{kg} \mathrm{Pu}$. If the standard deviation in Fig. 17 is taken as a measure of the accuracy for an arbitrary sample, then it appears to be better than 18 for ${ }^{239} \mathrm{Pu},{ }^{240} \mathrm{Pu}$, and ${ }^{241} \mathrm{Pu}$ and a few percent (limited somewhat by standards) for ${ }^{238} \mathrm{Pu}$ and ${ }^{241} \mathrm{Am}$.

Figures 18 and 19 show the precision for the isotopic fractions for two different burnups as a function of counting time. The isotopic fractions are listed by each curve. The predicted precision is that computed by the analysis program from propagated counting statistics. Figure 20 shows the precision of the specific power for the data shown in Figs. 18 and 19 . It is better than 18 for count times longer than $30 \mathrm{~min}$. For typical counting times of $2 \mathrm{~h}$, specific power precision is about $0.5 \%$.

Figure 21 shows the system with two detectors that can acquire data from two samples simultaneously. A sample platform above the detectors can be raised or lowered to tailor the count rate. The software will handle up to four detectors, so expansion up to four detectors can be accomplished by addition of only detectors and NIM electronics. This expansion has recently been completed. The single system can now acquire and analyze on-line data from four samples simultaneously.

\section{c. Mound}

The Mound Facility has been carrying out plutonium isotopic measurements in support of their calorimetry effort for some time. Mound researchers ${ }^{28}$ have automated the GRPANL peak-fitting code 27 from Livermore to produce the GRPAUT $^{16}$ program for isotopic analysis. The peak-fitting procedure follows the description outlined in Sec. VI.B. Isotopic ratios are measured. 


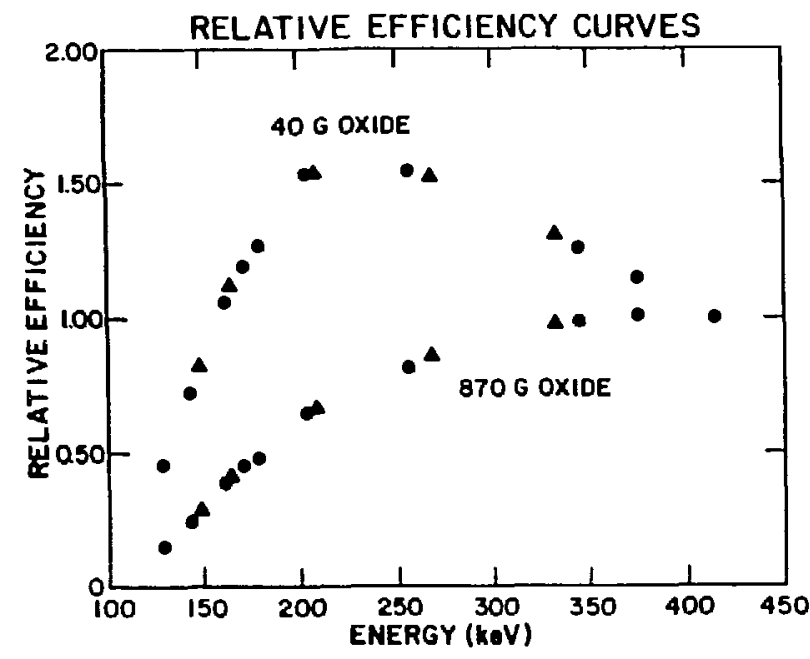

Fig. 16. Typical relative efficiency curves for two sample sizes with a 200-mm ${ }^{2}$ by 10-mm-deep planar HpGe detector. Solid circles from $239 \mathrm{Pu}$. Triangles from ${ }^{24} 1_{\mathrm{Pu}}$ and $241_{\mathrm{Pu}}{ }^{237} \mathrm{U}$.

Eig. 17. Los Alamos plutonium isotopic system accuracy for a wide range of samples.
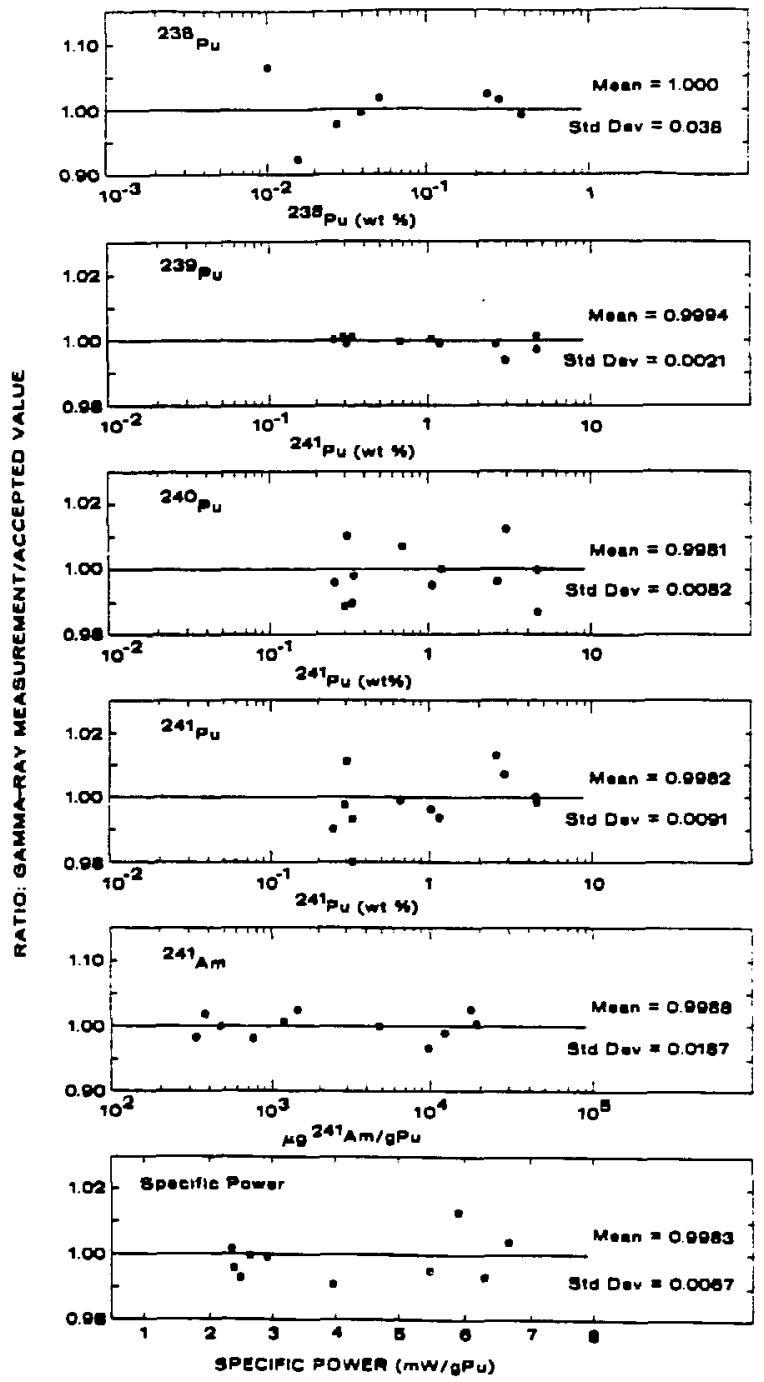


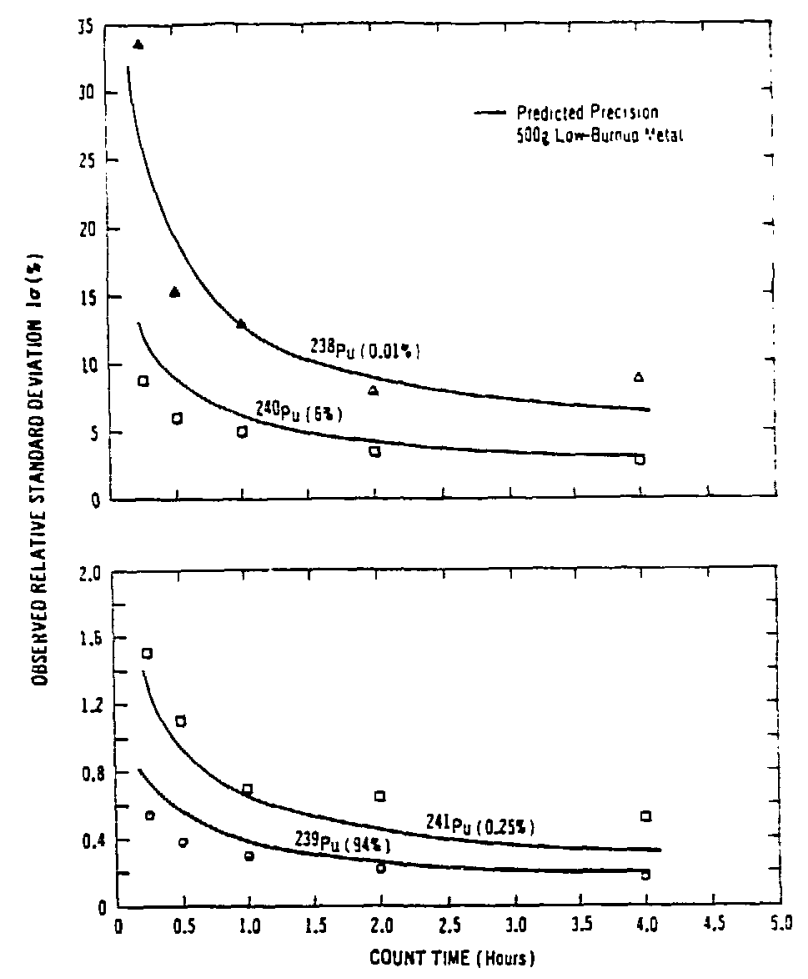

Fig. 18. Precision of isotopic fractions determined from 30 repeated measurements.

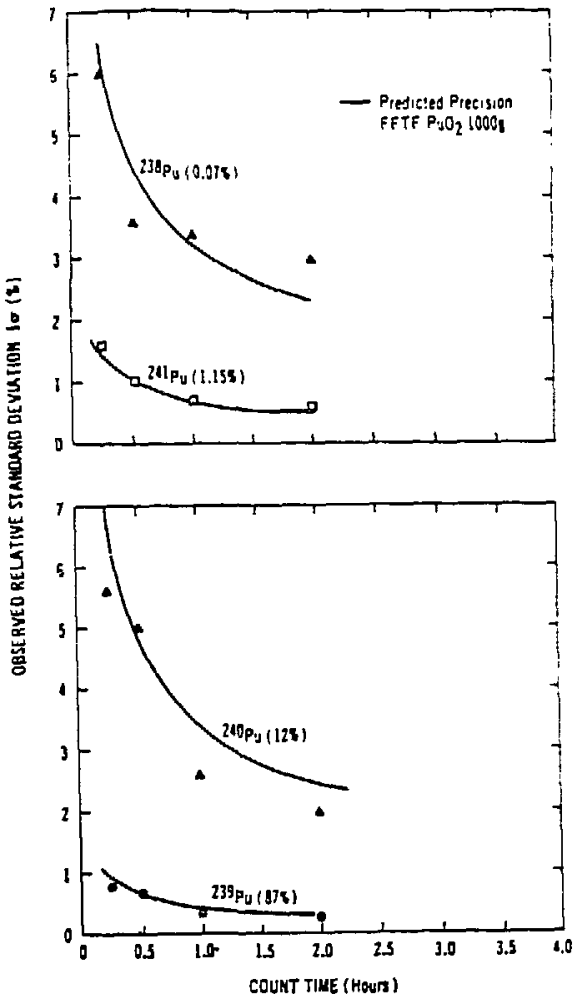

Fig. 19. Precision of 1sotopic fractions determined from 30 repeated measurements.

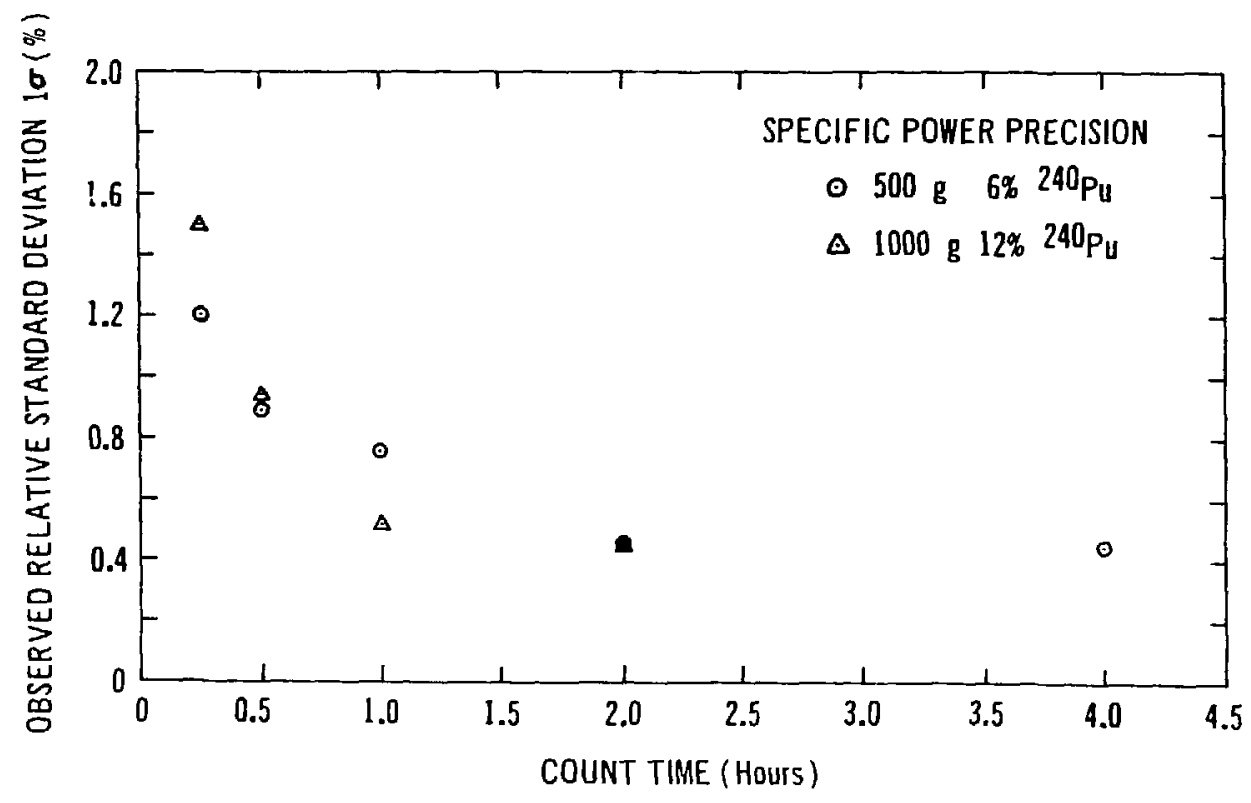

Fig. 20. Precision of specific power for 2 samples from 30 repeated measurements. 


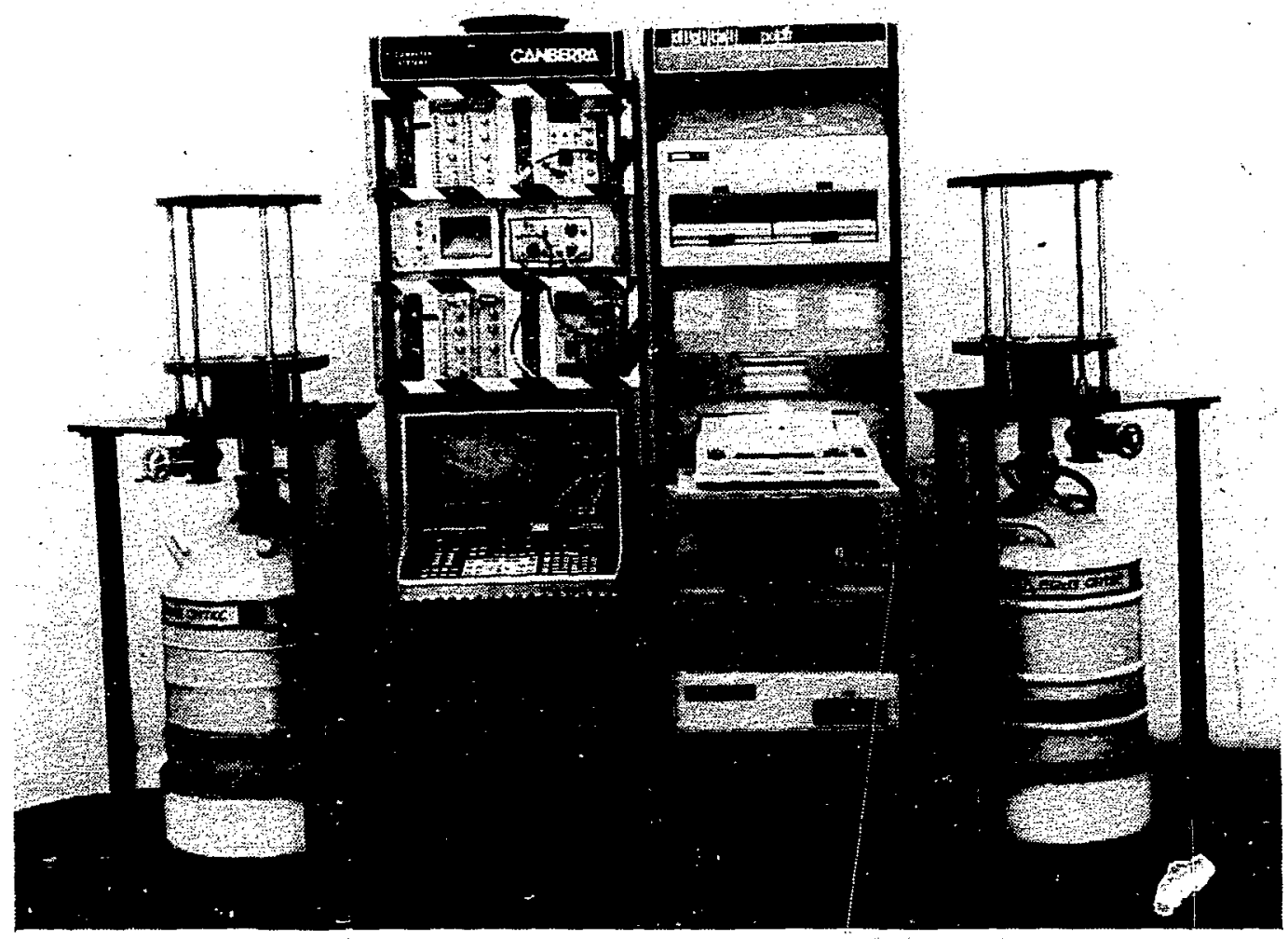

Fig. 21. Los Alamos multiple-detector plutonium isotopic system.

Long-term tailing is not used. The slope of the short-term tail is fixed during initial detector characterization. For each group fit, the peak height and FWHM are freed, and in some cases the short-term tail amplitude is also freed. Over 50 peaks are $f$ it in each spectrum in the region from 120 to $450 \mathrm{keV}$.

Because this method analyzes more peaks than do simple Ror methods, more isotopic ratio pairs can be formed. However, about the same ones as outlined in Table XV are used for the final ratios. Table XVI tabulates the ratios used in GRPAUT.

By using weignted least-squares techniques, investigators can fit relative efficiency curves to points from ${ }^{239} \mathrm{Pu}, 24 \mathrm{l}_{\mathrm{Pu}-}{ }^{237} \mathrm{U}$, and $24 \mathrm{Am}_{\mathrm{Am}}$. Normalization constants are used for the ${ }^{241} \mathrm{Pu}^{237} \mathrm{U}$ and ${ }^{241} \mathrm{Am}$ lines. The functional form of the relative efficiency curve is

$$
\ln \varepsilon_{i}=A_{0}+\sum_{j=1}^{2} A_{j} / E_{i}^{j}+\sum_{j=1}^{3} A_{j+2}\left(\ln E_{1}\right)^{j}+A_{6} \delta_{6}+A_{7} \delta_{7}
$$


PEAK RATIOS CALCULATED IN GRPAUT

Rat 1o

$241 / 239$

$238 / 239$

$238 / 241$

$240 / 239$

$240 / 241$

Am/ 239

\section{Energies}

$208 / 203 \mathrm{keV}^{\mathrm{a}}$

$148 / 144 \mathrm{keV}$

$165 / 161 \mathrm{keV}$

$148 / 129 \mathrm{kev}^{\mathrm{a}}$

$153 / 144 \mathrm{keV}$

$153 / 148 \mathrm{kev}^{\mathrm{a}}$

$160 / 161 \mathrm{keV}$

$160 / 165 \mathrm{keV}$

$160 / 148 \mathrm{kev}^{\mathrm{a}}$

$125 / 129 \mathrm{keV}$

$335 / 345 \mathrm{kev}^{\mathrm{a}}$

$369 / 375 \mathrm{kev}^{\mathrm{a}}$

aDenotes ratios used to calculate isotopic fractions. Weighted averages used where appropriate.

where $\varepsilon_{i}$ is the relative efficiency for a ganma ray of energy $E_{i}$. The

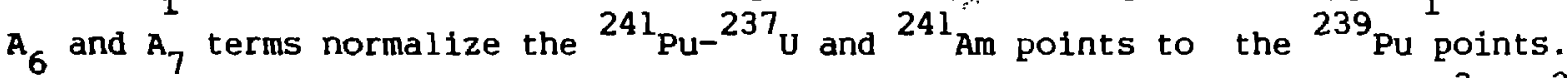
An isotopic correlation of the form of Eq. (13) $242=\mathrm{k} \times 240^{3} / 239^{2}$ is used to predict ${ }^{242} \mathrm{Pu}$.

Several studies have been published using the data analysis techniques of GRPAUT. A two-detector method ${ }^{19}$ uses a planar detector in the 120 - to $300-\mathrm{keV}$ region and a coaxial detector in the 300- to 700-keV region. The coaxial detector is heavily filtered to remove counts from photons below $200 \mathrm{keV}$. This procedure improves the ${ }^{240} \mathrm{Pu}$ and ${ }^{241} \mathrm{Am}$ measurement precision using the $642.48-\mathrm{keV}{ }^{240} \mathrm{Pu}$ and $662.42-\mathrm{keV} 24 \mathrm{Am}$ gamua rays. Quotable precision 
results $^{19}$ were similar for the $600^{-}$and $160-\mathrm{keV}$ regions with $-2 \%$ precision for the $160 / 148{ }^{240} \mathrm{Pu} /{ }^{241} \mathrm{Pu}$ ratio and the $642 / 646{ }^{240} \mathrm{Pu} /{ }^{239} \mathrm{Pu}$ ratio in a 50-ks counting time. For 241 An the $662 / 646^{241} \mathrm{Am} /{ }^{239} \mathrm{Pu}$ ratio was significantly more precise than the $125 / 1299^{241} \mathrm{Am} /{ }^{239} \mathrm{Pu}$ ratio for large samples.

Simultaneous calorimeter/gamma-ray assay 33,34 (Fig. 22) has the advantages of reducing operator radiation exposure through less sample handling and of reducing data transcriotion errers. Table XVII shows the results from simultaneous assay at three sit.. using a transportable system. These samples ranged from a few hundred grams to $2 \mathrm{~kg}$ of oxide and metal, most nominally $6 \%$ $\therefore 40 \mathrm{Pu}$. Count times were generally 10 to $50 \mathrm{ks}$.

This technique shows overall accuracy of better than $1 \%$ with measurement precision for total plutonium in the $1 \%$ to $3 \%$ RSD range.

The GRPAUT program has also been applied to the case of heterogeneous distribution of americium and plutonium as discussed previously. 23

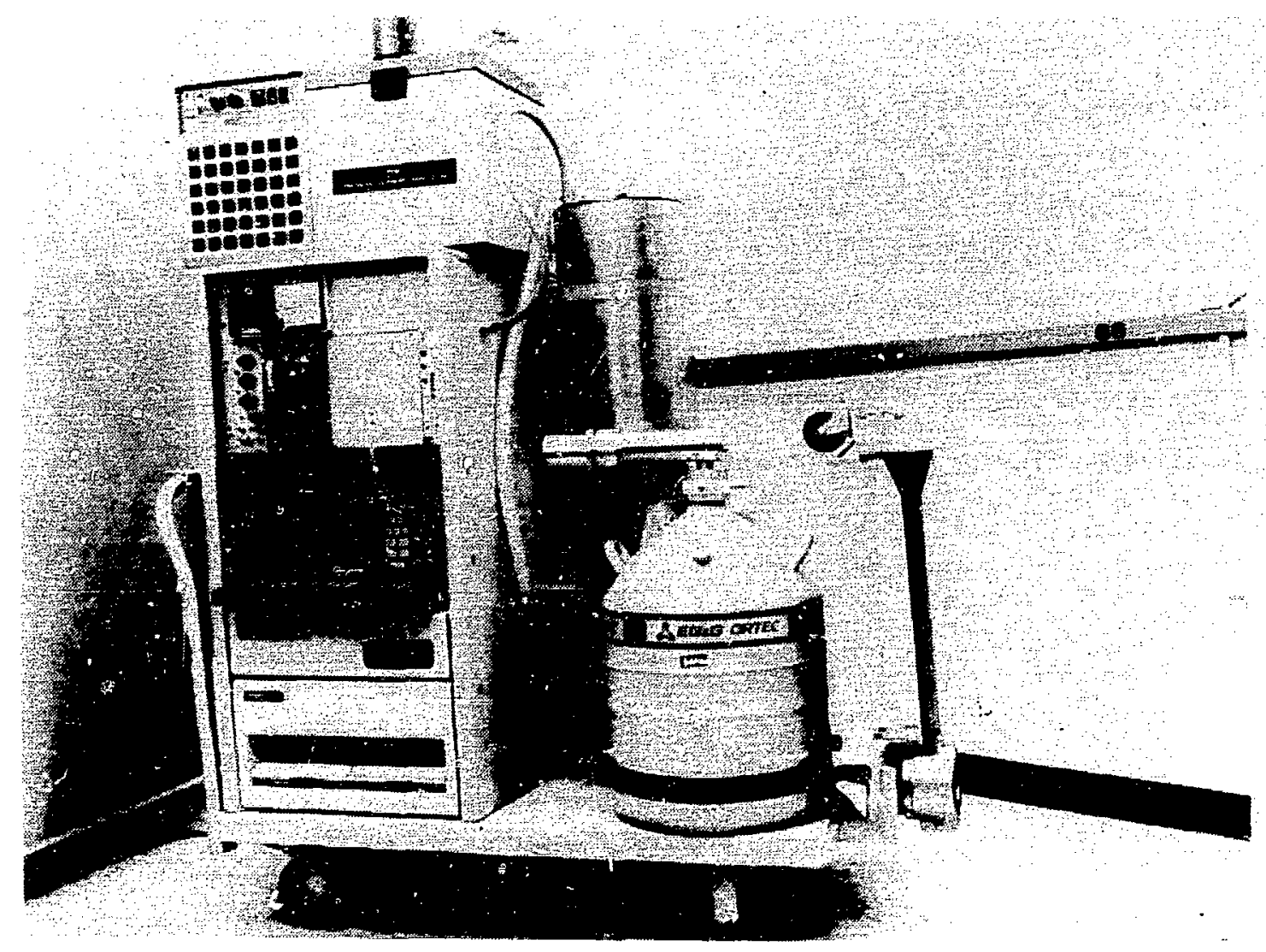

Fig. 22. Transportable calorimetry with simultaneous calorimetry/ gamma-ray spectroscopy capability. (Photo courtesy of J. G. Fleissner, Mound Facility.) 


\section{TABLE XVII}

SIMULTANEOUS ASSAY WITH TRANSPORTABLE CALORIMETER/ GAMMA-RAY SPECTROSCOPY SYSTEM 34

\begin{tabular}{|c|c|c|c|}
\hline site & $\begin{array}{l}\text { No. of } \\
\text { Samples }\end{array}$ & $\begin{array}{c}\text { Total Pu Assay } \\
\text { Average Ratio } \\
\text { Measured/Accepted }\end{array}$ & $\begin{array}{l}\text { Rel. Std. Dev. of } \\
\text { Individual Ratio }\end{array}$ \\
\hline 1 & 18 & 0.997 & 1.78 \\
\hline 2 & 20 & 1.007 & 0.78 \\
\hline 3 & 13 & 1.00 & 3.08 \\
\hline
\end{tabular}

\section{Livermore}

The response-function form of analysis has seen extensive use by Gunnink and coworkers at Livermore. One of the first implementations of this method was installed at the Savannah River Plant in the early 1970 s to measure lowconcentration solutions of low-burnup plutonium. Use of the l00-keV region and 40-keV region for Eresh samples erables one to obtain significantly better precision than methods using gamma rays above $120 \mathrm{keV}$. Table XVIII tabulates some resuits for this system.

For the freshly separated samples, measurement precision in only $10 \mathrm{~min}$ is within about a factor of 2 of that customarily assigned to mass spectrometry. The Savannah River system uses $10 \mathrm{ml}$ of solution in a plastic vial placed on top of the detector. The solution depth $(\sim 1 \mathrm{~cm})$ and low concentration combine to produce small attenuation sorrections for these samples.

This technique was applied later to reprocessing-plant solutions of high burnup $\left(\sim 208{ }^{240} \mathrm{Pu}\right)$ and high concentration $(\sim 250 \mathrm{~g} \mathrm{Pu} / \mathrm{l})$. $^{11}$ In this situation the 40-kev region is used for fresh solutions, as are the 129-keV ${ }^{239} \mathrm{Pu}$ and 148-keV ${ }^{241} \mathrm{Pu}$ peaks and the $94-\mathrm{keV}$ UKa $2 \times$ ray. Simple ROI integration is used for peak areas, with interferences stripped out channel by channel before suming. Ahsolute concentration for each isotope is measured with the system being calibrated with known solutions. The plutonium isotopic fractions are computed as outlined in Sec. IV.B. For aged solutions, response-function methods are applied to the 100-keV region. The 208- and 59-keV peaks are used for energy calibration and adjustment of peak-shape parameters. Numerous interferences are stripped out of the 100-kev complex before the response function fits are made. 
TABLE XVIII

FRESHLY SEPARATED SAMPLES

10-min MEASUREMENT, $3 \mathrm{~g} \mathrm{Pu} / \mathrm{l}$ SOLUTION 4

\begin{tabular}{|c|c|c|c|}
\hline Isotope & Abundance $(\xi)$ & Av Bias $(q)$ & Precision (\& RSD) \\
\hline 238 & 0.008 & 5.5 & 4.7 \\
\hline 239 & 93.46 & 0.048 & 0.049 \\
\hline 240 & 5.88 & 0.75 & 0.72 \\
\hline 241 & 0.65 & 0.96 & 1.9 \\
\hline
\end{tabular}

\begin{tabular}{|c|c|c|c|}
\hline Isotope & Abundance (8) & AV Bias (\%) & Precision ( 8 RSD) \\
\hline 238 & 0.018 & 7.6 & 5.7 \\
\hline 239 & 90.92 & 0.14 & 0.09 \\
\hline 240 & 8.40 & 1.6 & 0.94 \\
\hline 241 & 0.661 & 0.64 & 0.61 \\
\hline Am & - & 0.08 & 0.26 \\
\hline Total Pu & $5.4 \mathrm{~g} / \mathrm{l}$ & 0.46 & 0.35 \\
\hline
\end{tabular}

A very thin $(\sim \mathrm{mm}$ thick) sample cell, shown in Fig. 23, allows about a 0.25-ml sample to be viewed. The cell is mounted on the detector face as shown in Fig. 24.

Fresh solutions are counted for 15 to $30 \mathrm{~min}$; aged solutions are counted for $30 \mathrm{~min}$ to $1 \mathrm{~h}$. An isotopic correlation of the form of Eq. (12) is used to predict ${ }^{242} \mathrm{Pu}$.

Summarizing the large amount of data on process solutions taken with this system is difficult. Table XIX attempts to list the extremes for isotopic abundance, bias, and precision For both aged and fresh solutions.

Ruhter and came ${ }^{30}$ have also applied response-Eunction techniques to solid samples using gamma rays in the lizo- to 450-kev region. This analysis package ts made portable for use by International Atomic Energy Agency inspectors. 


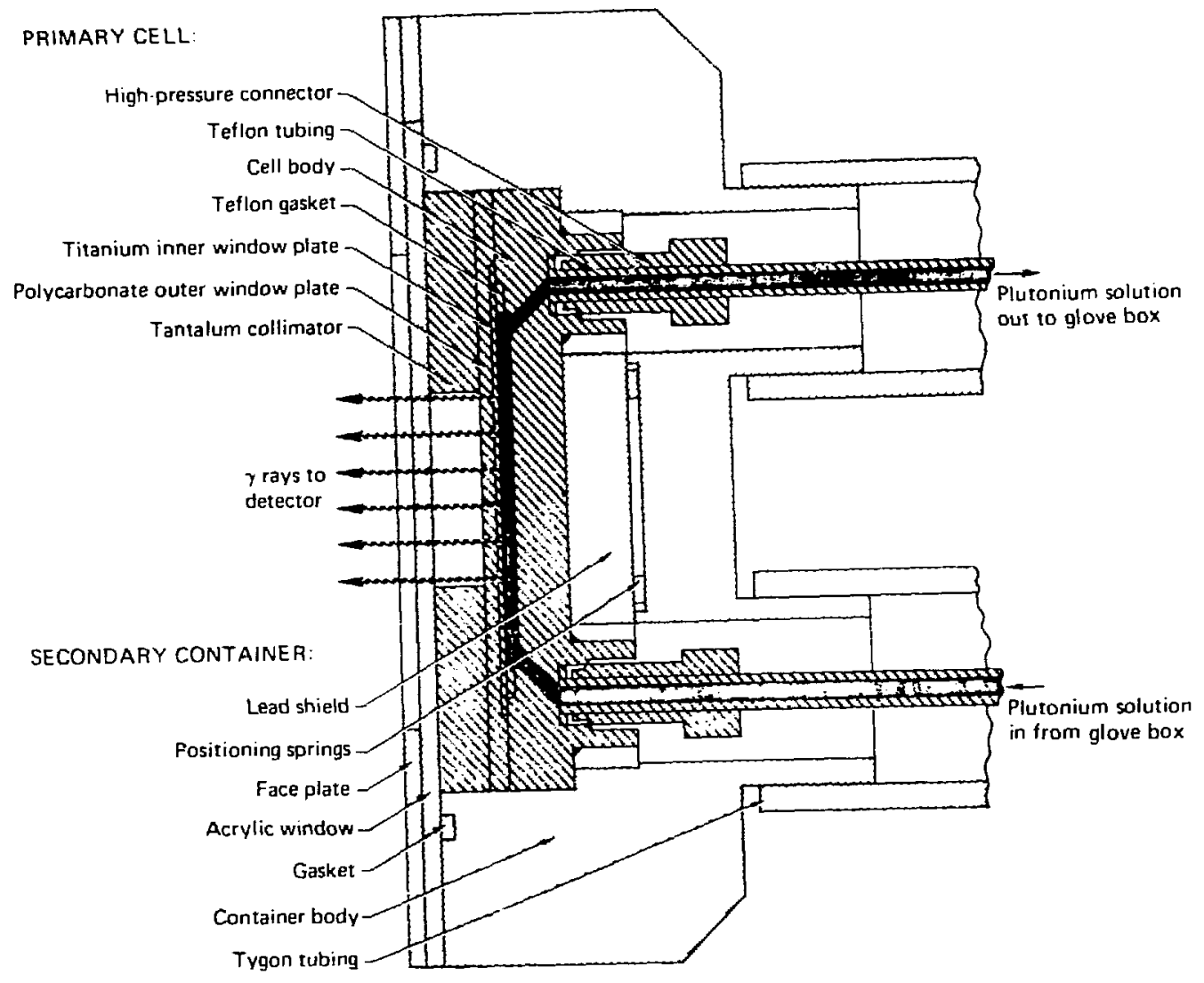

Fig. 23. Cutaway view of sample cell and double containment.11 (Photo courtesy of $R$. Gunnink, Lawrence Livermore National Laboratory.)

TABLE XIX

RE]PROCESSING PLANT SOLUTIONS, $130-270 \mathrm{~g}$ Pu/ $/, 94$ SAMPLES TASTEX TASK H PLUTONIUM ISOTOPICS 11

Abs. Value

Abs. Value

Isotope Abundance Range ( 8 )

Bias Range $(8)$

Precision Range ( $\%$ RSD)

238

$0.5-1.0$

$0.1-0.8$

$0.4-0.7$

239

$60-75$

$0.01-0.3$

$0.08-0.4$

240

$17-23$

$0.02-0.4$

$0.2-1.3$

241

$5-11$

$0.02-0.8$

$0.2-0.8$ 


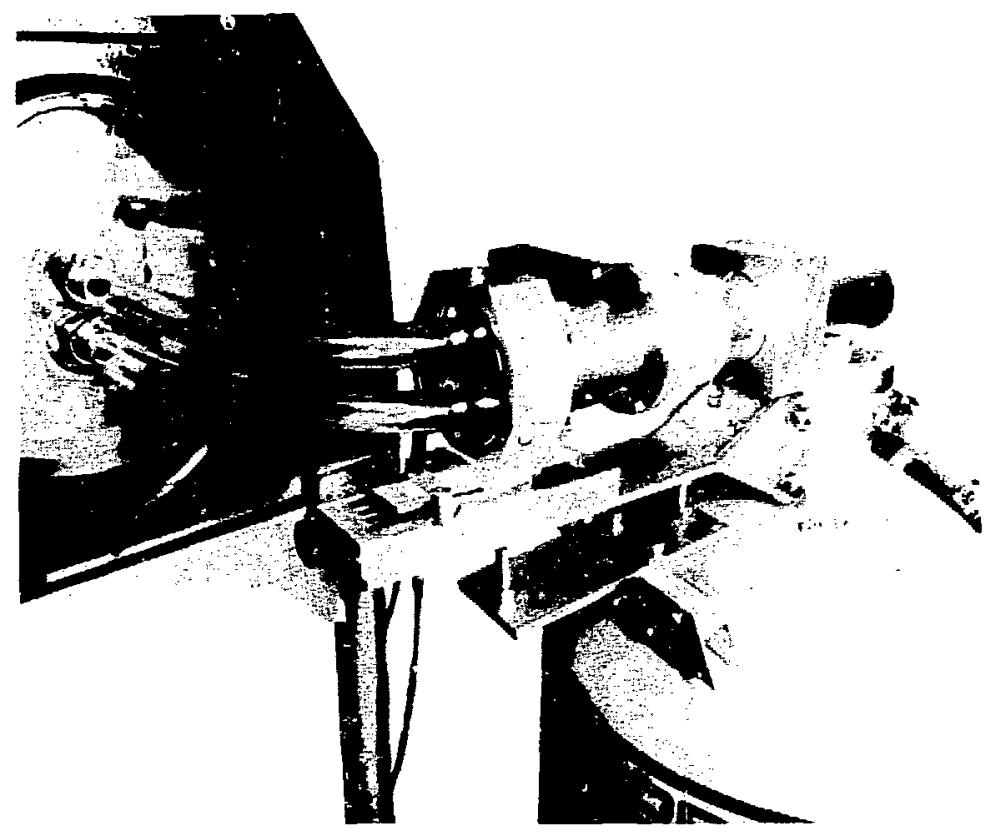

Fig. 24. Sample-cell assembly mounted on detector and coupled to glove box.11 (Photo courtesy of R. Gunnink, Lawrence Livermore National Laboratory.)

Another system described by Gunnink ${ }^{35}$ makes use of all the data available in the spectrum, accommodates two detectors (high and low energy), and analyzes data with both response functions and ROI peak integration. This system can obtain better precision than other methods for arbitrary samples because of its response-function analysis of the $100-\mathrm{keV}$ region.

\section{E. Precision Summary}

Measurement precision is influenced most by the spectral region analyzed, with higher precision obtained for the lower energy regions that have higher emission rates. In Table $\mathrm{XX}$ we attempt to sumnarize the measurement precision attainable for different energy regions, with the ranges corresponding to a reasonable range of count times and isotopic abundances. Accuracy is usually commensurate with precision. 
TABLE XX

TYPICAL MEASUREMENT PRECISION (\& RSD)

\begin{tabular}{|c|c|c|c|c|c|c|c|}
\hline $\begin{array}{l}\text { Energy Reglon } \\
\text { (keV) }\end{array}$ & Count Times & 238 & 239 & 240 & 241 & Am & $\begin{array}{l}\text { Specif ic } \\
\text { Power }\end{array}$ \\
\hline 40 & 10-30 min & $0.3-5$ & $0.05-0.5$ & $0.2-1.0$ & $0.2-1.0$ & - & - \\
\hline 100 & $30-60 \mathrm{~min}$ & $0.3-5$ & $0.05-0.5$ & $0.2-1.0$ & $0.2-0.8$ & $0.1-1.0$ & $0.1-1.0$ \\
\hline$>120$ & $1-4 h$ & $<1-10$ & $0.1-0.5$ & $1-5$ & $0.3-0.8$ & $0.2-10$ & $0.3-2$ \\
\hline
\end{tabular}

ACKNOWLEDGMENTS

R. A. Hamilton, J. Fleissner, and R. Gunnink have graclously provided information and photographs of their systems. Spectral data plotting and labeling were done by $E$. L. Sandford.

\section{REFERENCES}

1. Francis X. Haas and walter Strohm, "Gamma-Ray spectrometry for Calorimetric Assay of Plutonium Fuels," IEEE Trans. Nucl. Sci. NS-22, 734 (1975).

2. T. Dragnev and K. Scharf, "Nondestructive Gamma Spectrometry Measurement of $239_{\mathrm{Pu}} / 240_{\mathrm{Pu}}$ and $\mathrm{Pu} / 240_{\mathrm{Pu}}$ Rátios," Int. J. Appl. Radiat. Isot. 26. 125 (1975).

3. J. L. Parker and T. D. Reilly, "Plutonium Isotopic Determination by GammaRay Spectroscopy," in "Nuclear Analysis Research and Development Program Status Report, January-April 1974," G. R. Keepin, Ed., Los Alamos Scientific Laboratory report LA-5675-PR (August 1974).

4. R. Gunnink, J. B. Niday, and P. D. Siemens, "A System For Plutonium Analysis by Gamma-Ray Spectrometry. Part 1: Techniques For Analysis of Solutions," Lawrence Livermore Laboratory report UCRL-51577, Part 1 (April 1974).

5. R. Gunnink, "A Simulation study of Plutonium Gamma-Ray Groupings For Isotopic Ratio Determinations," Lawrence Livermore Laboratory report UCRL-51605 (June 1974).

6. R. D. Evans, the Atomic Nucleus (McGraw Hill Book Company, Inc., New York, $1955)$, p. 484 .

7. R. Gunnink, "Use of Isotope Correlation Techniques to Determine ${ }^{242} \mathrm{Pu}$ Abundance," J. Inst. Nucl. Mater. Manage. 9 (2), 83-93 (1980). 
8. R. Gunnink, J. E. Evans, and A. L. Prindle, "A Reevaluation of the Gamma-Ray Energies and Absolute Branching Intensities of $237 \mathrm{U}$, 238, 239, 240, 24l $\mathrm{Pu}$, and $241_{\mathrm{Am}}$," Lawrence Livermore Laboratory report UCRL-52139 (October 1976).

9. J. F. Lemming and D. A. Rakel, "Guide to Plutonium Isotopic Measurements Using Gamma-Ray Spectrometry," Mound Facility report MLM-298l (August 1982).

1.0. P. A. Russo, S. T. Hsue, J. K. Sprinkle, Jr., S. S. Johnson, Y. Asakura, I. Kando, J. Masui, and K. Shoji, "In-Plant Measurements of Gamma-Ray Transmissions for Precise $K$-Edge and Passive Assay of Plutonium Concentration and Isotopic Fractions in Product Solutions," Los Alamos Nat Lonal Laboratory report LA-9440-MS (PNCT 84l-82-10) (August 1982).

11. R. Gunnink, A. L. Prindle, Y. Asakura, J. Masui, N. Ishiguro, A. Kawasaki, and S. Kataoka, "Evaluation of TASTEX Task $\mathrm{H}$ : Measurement of Plutonium Isotopic Abundances by Gamma-Ray Spectrometry." Lawrence Livermore National Laboratory report UCRL-52950 (October 196i).

12. H. Umezawa, T. Suzuki, and S. Ichikawa, "Gamma-Ray Spectrometric Determination of Isotopic Ratios of Plutonium," J. Nucl. Sci. Technol. 13 , 327-332 (1976).

13. J. Bubernak, "Calibration and Use of a High-Resolution Low-Energy Photon Detector for Measuring Plutonium Isotopic Abundances," Anal. Chim. Acta 96. 279-284 (1978).

14. T. K. Li, T. E. Sampson, and 5. S. Johnson, "Plutonium Isotopic Measurement for Small product Samples," Proceedings of Fifth Annual ESARDA Symposium on Safequards and Nuclear Material Management, Versailles, France, April 19-21, 1983 (ESARDA 1983), ESARDA 16, Pp. 289-291.

15. R. Gunnink, "Gamma Spectrometric Methods For Measuring Plutonium," Proceedings of the American Nuclear Society National, Topical Meeting on Analytical Methods for Safeguards and Accountabllity Measurements of Special Nuclear Material, villiamsburg, Virginia, May 15-17, 1978.

16. J. G. Fleissner, "GRPAUT: A Program for Pu Isotop1c Analysis (A User's Guide)," Mound Facility report MLM-2799 (ISPO-128) (January 1981).

1.7. T. E. Sampson, S. T. Hsue, J. L. Parker, S. S. Johnson, and D. F. Bowersox, "The Determination of Plutonium Isotopic Composition by GammaRay Spectroscopy," Nucl. Instr. Meth. 193, 177-i83 (1982).

18. H. Ottmar, "Results Erom An Interlaboratory Exercise on the Determination of Plutonium Isotopic Ratios by Gamma Spectrometry." Kernforschungszentrum Karlsruhe report KfK 3149 (ESARDA 1/81) (July 1981). 
19. J. G. Fle1ssner, J. F. Lemming, and J. Y. Jarv1s, "Study of a Two-Detector Method for Measuring Plutonium Isotopics," in Proceedings of American Nuclear Soclety Topical Meeting on Measurement Technology for Safeguards and Materials Control, Kiawah Island, South Carolina, Nov. 26-30, 1979 (Nati nal Bureau of Standards, Special Publication 582, washington, DC, 1980), pp. 555-567.

20. H. Unezawa, H. Okashita, and S. Matsurra, "Studies on Correlation Among Heavy Isotopes in Irradiated Nuclear Fuels," Symposium on Isotopic Correlation nd Its Application to the Nuclear Fuel cycle held by ESARDA, Stresa, italy, May 1978.

21. K. Kandiah and G. White, "Status at Harwell of Opto-Electronic and Time Variant Signal Processing for High Performance Nuclear Spectrometry with Semi-Conductor Detectors," IEEE Trans. Nucl. Sci. NS-28 (1) (1981).

22. F. J. G. Rogers, "The Use of a Microcomputer with In-Field Nondestructive Assay Instruments," International Symposium on Recent Advances in Nuclear Materials Safeguards, International Atomic Energy Agency, Vienna, Austria, November $8-12,1982$.

23. J. G. Fleissner, "Nondestructive Assay of Plutonium Isotopically Heterogeneous Salt Residues," Proceedings of the conference on Safeguards Technology: The Process-Safeguards Interface, Nov. 28-Dec.2, 1983, Hilton Head Island, South Carolina, CONF-831106, pp. 275-285.

24. R. H. Auguston and T. D. Reilly, "Fundamentals of Passive Nondestructive Assay of Fissionable Material," Los Alamos scientific Laboratory report LA-5651-M (September 1974).

25. R. Gunnink, "Computer Techniques for Analysis of Gamma-Ray Spectra." Lawrence Livermore Laboratory report UCRL-80297 (1978).

26. R. Gunnink and J. B. Niday, "Computerized Quantitative Analysis by GammaRay Spectrometry Vol. 1. Description of the Gamanal Program," Lawrence Liverinore Laboratory report UCRL-51061, Vol. I (March 1972).

27. R. Gunnink and W. D. Ruhter, "GRPANL: A Program for Fitting Complex Peak Groupings for Gamma and X-Ray Energies and Intensities," Lawrence Livermore Laboratory report UCRL-52917 (January 1980).

28. J. G. Fleissner and R. Gunnink, "GRPNL 2: An Automated Program for Fitting Gamna and X-Ray Peak Multiplets." Mound Facility report MLM-2807 (March 1981).

29. R. Gunnink, "An Algorithm for Fitîng Lorentzian-Broadened K-Series X-Ray Peaks of the Heavy Elements," Nucl. Instr. Meth. 143, 145 (1977).

30. W. D. Ruhter and D. C. Camp, "A Portable Computer to Reduce Gama-Ray Spectra for Plutonium Isotopic Ratios," Lawrence Livermore National Laboratory report UCRL-53145 (May 1981). 
31. Letter and attachments from R. A. Hamilton to T. E. Sampson, February 24, 1983. Rockwell-Hanford Letter No. R83-0763.

32. S. T. Hsue, T. E. Sampson, J. L. Parker, S. S. Johnson, and D. F. Bowersox, "Plutonium Isotopic Composition by Gamma-Ray Spectroscopy," Los Alamos Scientific Laboratory report LA-8603-MS (November 1980).

33. D. A. Rakel, "Gamna-Ray Measurements for Simultaneous Calorimetric Assay," Nucl. Mater. Manage. X, 467 (1981).

34. D. A. Rakel, J. F. Lemning, W. W. Rodenburg, M. F. Duff, and J. Y. Jarvis. "Results of Field Tests of a Transportable calorimeter Assay System," 3rd Annual ESARDA Symposium on Safeguards and Nuclear Materials Management. Karlsruhe, Federal Republic of Germany, May 6-B, 1981, p. 73.

35. R. Gunnink, "Plutonium Isotopic Analysis of Nondescript Samples by GamnaRay Spectrometry," Conf. on Analytical Chemistry in Energy Technology. Gätlinburg, Tennessee, October 6-8, 1981. 